Review

\title{
The Potential Use of Natural and Structural Analogues of Antimicrobial Peptides in the Fight against Neglected Tropical Diseases
}

\author{
Lewies Angélique, Wentzel Johannes Frederik, Jacobs Garmi and Du Plessis Lissinda Hester * \\ Centre of Excellence for Pharmaceutical Sciences (PHARMACEN), North-West University, \\ Potchefstroom 2520, South Africa; E-Mails: 20577966@nwu.ac.za (L.A.); \\ 20134045@nwu.ac.za (W.J.F.); 22119027@nwu.ac.za (J.G.) \\ * Authors to whom correspondence should be addressed; E-Mail: Lissinda.DuPlessis@nwu.ac.za; \\ Tel.: +27-018-299-4246; Fax: +27-087-231-5432.
}

Academic Editor: Thomas J. Schmidt

Received: 13 July 2015 / Accepted: 10 August 2015/ Published: 24 August 2015

\begin{abstract}
Recently, research into the development of new antimicrobial agents has been driven by the increase in resistance to traditional antibiotics and Emerging Infectious Diseases. Antimicrobial peptides (AMPs) are promising candidates as alternatives to current antibiotics in the treatment and prevention of microbial infections. AMPs are produced by all known living species, displaying direct antimicrobial killing activity and playing an important role in innate immunity. To date, more than 2000 AMPs have been discovered and many of these exhibit broad-spectrum antibacterial, antiviral and anti-parasitic activity. Neglected tropical diseases (NTDs) are caused by a variety of pathogens and are particularly wide-spread in low-income and developing regions of the world. Alternative, cost effective treatments are desperately needed to effectively battle these medically diverse diseases. AMPs have been shown to be effective against a variety of NTDs, including African trypanosomes, leishmaniosis and Chagas disease, trachoma and leprosy. In this review, the potential of selected AMPs to successfully treat a variety of NTD infections will be critically evaluated.
\end{abstract}

Keywords: antimicrobial peptides (AMPs); neglected tropical diseases (NTDs); malaria; parasites; antibacterial; antiviral; parasitic worms; innate immunity 


\section{Introduction}

At the beginning of the new millennium, the international community, led by the United Nations, committed themselves to the Millennium Development Goals in order to drastically reduce extreme poverty and combat disease amongst the poorest populations of the world. Now, at the end of the 15 year period of this ambitious action plan, we can look back and evaluate the successes and shortcomings of this development framework. The sixth goal of this framework is to combat HIV/AIDS, malaria and other diseases. This goal has brought much-needed attention to neglected diseases, leading to the establishment of the Global Network for Neglected tropical diseases Control and a World Health Organisation (WHO) department, specifically tasked to address neglected tropical disease-related issues. Neglected Tropical Diseases (NTDs) are a diverse group of 17 disabling conditions, mostly affecting the world's poorest populations [1]. These diseases affect more than 1.4 billion people around the world, causing more than half a million deaths annually [1,2]. Although these diseases distress a considerable portion of the global population, they may be considered "neglected" due to the dire lack of effective treatments and funding [3]. Despite all the positive progress from the Millennium Goals framework, NTDs still cause massive global suffering in millions of people. New treatment strategies are desperately needed to ease the burden caused by these tropical diseases.

The emerging and increasing resistance to antibiotics has become a threat to global public health and is driving novel research into the development of new antimicrobial agents. AMPs are promising candidates as alternatives to current antibiotics in the treatment and prevention of microbial infections [4-6]. Although there are a number of AMPs in clinical development $[4,7,8]$, only a few have been successfully applied commercially. Perhaps the best known is the lantibiotic nisin (APD ID: AP00205) produced by the gram-positive bacterium Lactococcus lactis. This AMP exhibits antimicrobial activity against many gram-positive bacteria, including food-borne pathogens such as Staphylococcus aureus and Listeria monocytogenes, is not toxic to animals and was approved by the WHO in 1969 and the US Federal Food and Drug Administration (FDA) in 1988 for the use as a food preservative [9]. AMPs not only have broad-spectrum antibacterial activity, but also display antiviral and anti-parasitic activity [10] and therefore have potential for use in the treatment of a wide variety of NTDs. On the other hand, some of these microbes, for example the filarial worm Onchocerca volvulus [11], could prove to be a source of novel AMPs with therapeutic potential against microbial infections.

The aim of this review is to critically evaluate the potential of selected AMPs (both natural and structural analogues of natural AMPs) to successfully treat a variety of NTDs and malaria. NTDs that are covered include those caused by bacteria (leprosy/Hansen disease and trachoma), protozoa (chagas disease, human African trypanosomiasis and leishmaniosis), helminths (taeniasis and onchocerciasis) and viruses (dengue viral disease and rabies).

\section{Antimicrobial Peptides}

Antimicrobial peptides (AMPs) are considered natural antibiotics and are produced by all known living species, ranging from bacteria, fungi, and plants to invertebrates, non-mammalian vertebrates and mammals. To date, more than 2000 AMPs from various sources with a broad range of activities (ranging from antimicrobial activity to anticancer, spermicidal, chemotactic or antiviral activity) have 
been listed on APD2 [12], a database largely dedicated to natural AMPs [13,14]. For the scope of this review, only AMPs that are ribosomally synthesised [15] will be included in order to distinguish them from classical natural peptide antibiotics, such as vancomycin, which are assembled by non-ribosomal peptide synthetases [16]. Non-ribosomally synthesised AMPs can however be found in lower organisms such as bacteria, for example baceridin (APD ID: AP02372) which has recently been isolated from a plant-associated Bacillus strain [17,18]. Gene-encoded, ribosomally synthesised AMPs are evolutionary conserved components of the innate immune system, which serve as a first line of defence against microbial infections $[19,20]$ and are therefore also referred to as host defence peptides. Foregoing the adaptive immune response (humoral and cell mediated immunity), the innate immune system can be mobilized against a variety of microorganisms, even if the host is encountering these microbes for the first time. After the initial infection, the interferon (IFN) response can be triggered by the recognition of foreign gene segments (this includes genomic dsRNA/DNA, mRNA and replication intermediates) or proteins by pattern recognition receptors (PRR). PRRs are divided into two families: (1) the cytoplasmic pathogen detectors which include the RNA sensitive retinoic acid-induced gene (RIG-I) and melanoma differentiation associated gene 5 (MDA5); and (2) the trans-membrane toll-like receptors (TLR) [21-23]. The recognition of alien genomic material by these PRRs triggers a complex cascade of cellular events which finally concludes with the deployment of immune regulatory proteins. Bacteria and fungi are also known to utilize cytolytic and antimicrobial peptides to obtain a competitive advantage over other micro-organisms in their habitat [24]. These peptides also play an important role in the innate immune system of most plants and animals [25].

\subsection{Classification of AMPs}

The selectivity and antimicrobial potency of AMPs towards microbes are determined by structural parameters including net charge and structural conformation [26,27]. Although structurally based classifications are generally used to divide AMPs into subgroups, AMPs may also be classified according to their net charge, which is determined by their amino acid composition.

\subsubsection{Classification of AMPs According to Net Charge}

Based on the net charge, AMPs can be divided into anionic AMPs (AAMPs) and cationic AMPs (CAMPs). AAMPs are rich in aspartic and glutamic acid and consist of 5 to 70 amino acids with a net negative charge of -1 to -7 [28,29]. CAMPs are the most abundant form of AMP found in nature and are also the most thoroughly studied for therapeutic use. Hence, this review will primarily focus on the use of CAMPs for the treatment of selected NTDs. For a comprehensive overview of AAMPs, see Harris et al. [28]. CAMPs (from here on referred to simply as AMPs) typically consist of 12 to 100 amino acids with a net positive charge of +2 to +9 due to the excess of basic amino acids (arginine, lysine and/or histidine) compared to acidic amino acids [10].

\subsubsection{Classification According to Secondary Structure}

Despite being small in size, AMPs can be divided into three major structural classes (Figure 1) based on their secondary structure [27,30-32]: 
i a-helical AMPs: These peptides are unstructured linear peptides free of cysteine residues that fold into $\alpha$-helixes upon contact with membranes. They consist of approximately $50 \%$ hydrophobic residues, favouring an amphiphilic conformation upon interaction with membranes, which enables them to permeabilise microbial membranes. Some of these peptides are not strictly $\alpha$-helical and may possess an internal kink and/or a flexible unstructured segment at the N- and/or C-terminus. For example, melittin (APD ID: 00146) (Figure 1A) from bee venom and the human cathelicidin LL-37 (APD ID: AP00310) (Figure 1B).

ii Linear/extended AMPs: These peptides are linear without cysteine residues and contain a high proportion of proline, arginine, glycine, tryptophan and histidine. Some of these AMPs form extended coils. Examples include indolicidin (APD ID: AP00150) (Figure 1C) from bovine leukocytes.

iii $\boldsymbol{\beta}$-sheet AMPs: These peptides contain six to eight cysteine residues, forming two or more disulphide bonds, resulting in a stabilized $\beta$-sheet structure. For example $\alpha$ and $\beta$ defensins such as human neutrophil peptide-1 (HNP-1, APD ID: AP00176) (Figure 1D) from mammals.

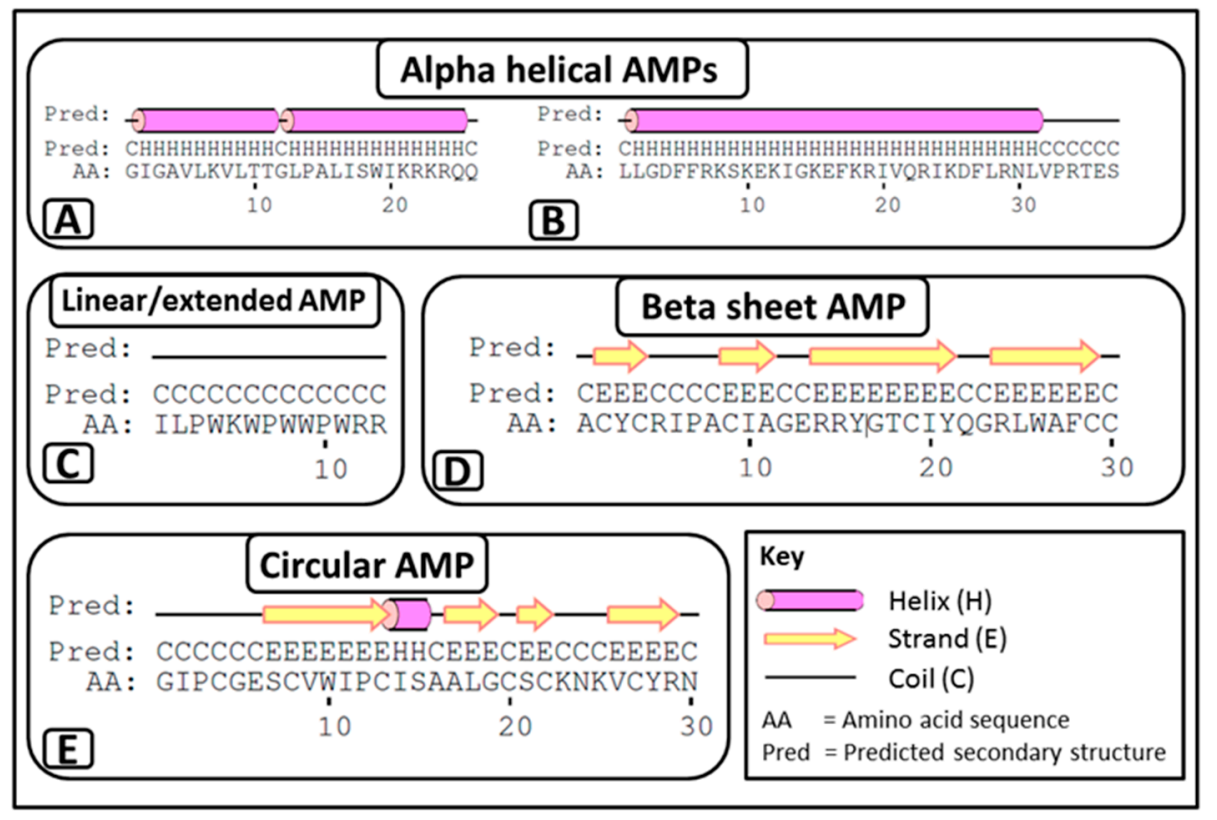

Figure 1. Secondary structures of the three major AMP classes. Examples of $\alpha$-helical AMPs include (A) melittin, two $\alpha$-helixes joined by a hinge between residues 11-12; and (B) LL-37, $\alpha$-helix with an unstructured segment at the C-terminal; (C) indolicidin, which can be classified as an extended coil; and (D) human neutrophil peptide 1, which is an example of a $\beta$-sheet. In addition to the three major classes, circular AMPs including (E) circulin A, consisting of both $\alpha$-helix and $\beta$-sheet structures, are also found in nature. Secondary structures were generated with the PSIPRED protein prediction server [33]. Disulphide bonds are not shown.

AMPs that do not typically fit into the previous three secondary structural classes are classified as circular AMPs [34]. The plant-derived circulin A (APD ID: AP00274) (Figure 1E) from the Chassalia parviflora species can be categorised into this group. Circulin A consists of a combined $\alpha$-helix and $\beta$-sheet structure [35] and forms the so-called cyclic cysteine knot [36]. Though they display 
$\beta$-sheet-like structures, $\Theta$ defensins can also be classified into this group, as they form cyclic octadecamers, which consist of two antiparallel $\beta$-sheets linked by three disulphide bonds [37].

The major forms of AMPs found in mammals are cathelicidins and defensins, although they are also found in non-mammals such as birds [38,39], fish [40,41], reptiles [42,43] and even plants [44] and insects [45]. Cathelicidins and defensins have been extensively reviewed elsewhere [46-50] and will therefore not be discussed in detail in this review.

\subsection{Target Organisms and Mode of Action of AMPs}

AMPs have broad-spectrum antibacterial, antiviral, antifungal and anti-parasitic activities. There are also AMPs that display anti-protist activity. A single AMP can have a single microbial target or have multiple microbial targets simultaneously, i.e., displaying broad spectrum antibacterial activity, as well as being antifungal, anti-parasitic and antiviral (Table 1) [13,14].

Table 1. Antimicrobial peptides which display antibacterial (gram positive and negative) as well as antiviral, antifungal and anti-parasitic activity $[13,14]$.

\begin{tabular}{|c|c|c|c|c|}
\hline AMP & APD ID & Source & Sequence & Structure \\
\hline Magainin 2 & AP00144 & $\begin{array}{c}\text { African clawed frog } \\
\text { (Xenopus laevis) }\end{array}$ & GIGKFLHSAKKFGKAFVGEIMNS & $\alpha$-helix \\
\hline Melittin & AP00146 & $\begin{array}{c}\text { Honey bee } \\
\text { (Apis mellifera) (also } \\
\text { A.florea, A. cerana) }\end{array}$ & GIGAVLKVLTTGLPALISWIKRKRQQ & $\alpha$-helix \\
\hline Dermaseptin-S1 & AP00157 & $\begin{array}{c}\text { Sauvages leaf frog } \\
\text { (Phyllomedusa sauvagii) }\end{array}$ & ALWKTMLKKLGTMALHAGKAALGAAADTISQGTQ & $\alpha$-helix \\
\hline HNP-1 & AP00176 & $\begin{array}{c}\text { Human } \\
\text { (Homo sapiens) }\end{array}$ & ACYCRIPACIAGERRYGTCIYQGRLWAFCC & $\beta$-sheet \\
\hline LL-37 & AP00310 & $\begin{array}{c}\text { Human (Homo sapiens) } \\
\text { Chimpanzee } \\
\text { (Pan troglodytes) }\end{array}$ & LLGDFFRKSKEKIGKEFKRIVQRIKDFLRNLVPRTES & $\alpha$-helix \\
\hline BMAP-27 & AP00366 & $\begin{array}{c}\text { Domestic cattle } \\
\text { (Bos taurus })\end{array}$ & GRFKRFRKKFKKLFKKLSPVIPLLHLG & $\alpha$-helix \\
\hline
\end{tabular}

\subsubsection{Perturbation of the Microbial Membranes by AMPs}

Biophysical properties such as the secondary structure, net charge and hydrophobicity influence the interaction of AMPs with membranes as determined via experimentation with model and biological membranes [10,51,52]. Although, investigations of membrane mediated microbial activities of AMPs focuses mainly on bacteria [25,53], AMPs have also been found to display direct killing action against parasites [54], fungi [55] and enveloped viruses [56] through direct membrane or capsid interactions (Figure 2). The mechanism of interaction will differ depending on the microbial organism and the AMP under investigation, but generally the initial attraction between an AMP and the microbial membrane occur through electrostatic interactions. The cationic property of AMPs allow them to target negatively charged microbial membranes opposed to neutral zwitterionic phospholipid containing bilayer membranes of mammalian cells. The higher levels of cholesterol in mammalian cells can further be used as basis for 
AMPs to distinguish between microbial and mammalian cell membranes [53]. Although in most cases there seems to be no specific receptors for peptide binding, in the case of viruses, AMPs are thought to disrupt the viral capsid or interfere with host entry by binding to the viral glycoproteins [57]. Following binding of AMPs to cell membranes, cell death can occur by disrupting membrane integrity, resulting in the leakage of the cytoplasm, depolarization and osmotic imbalance, swelling of the cells and, finally, cell lysis [54,58,59].

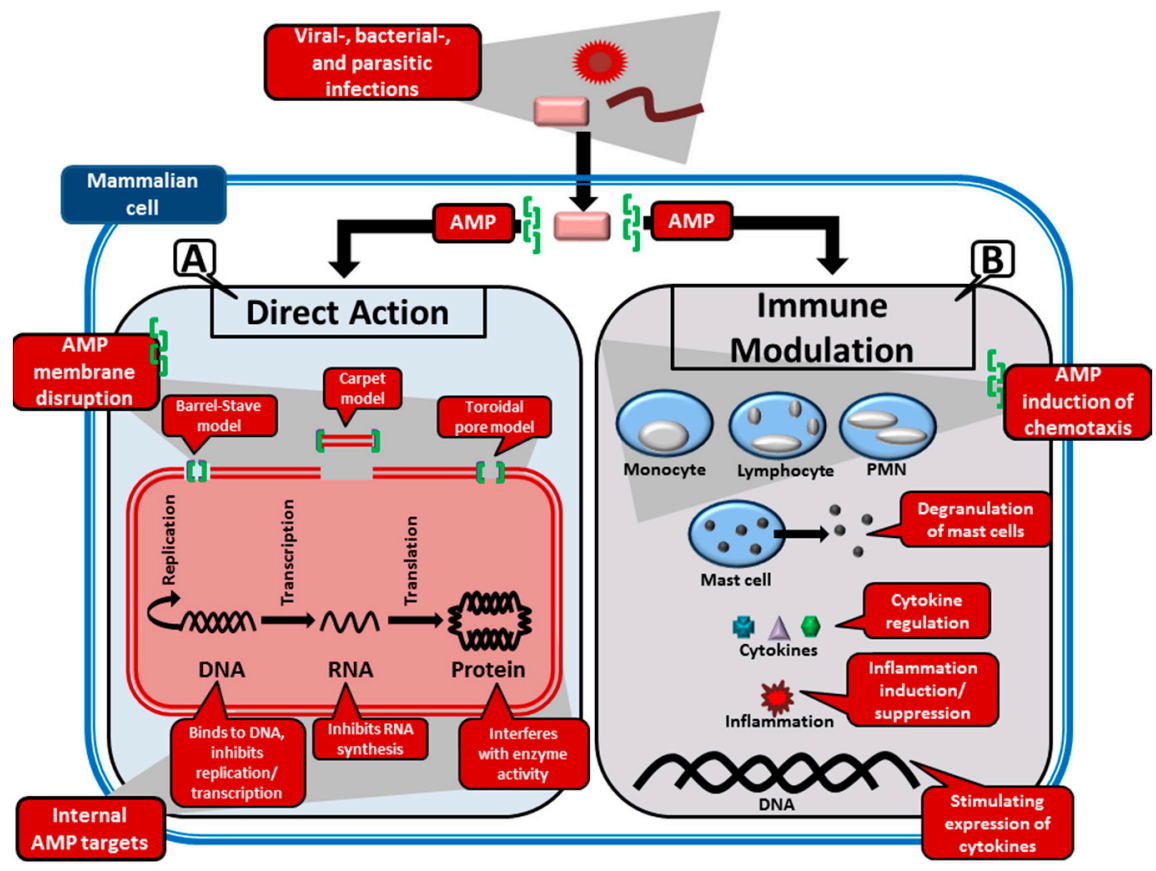

Figure 2. Main antimicrobial mechanisms of AMPs during the infection of a mammalian host cell. (A) The direct microbial action of AMPs involves the binding of these peptides to the microbial membrane/capsid, resulting in the infectious agent's neutralization. There are three models proposed for this action: (i) the barrel-stave model, where the AMPs embed themselves into the membrane to form pores; (ii) the carpet model, which proposes that small portions of the membrane be removed by AMPs; and (iii) the toroidal model, which is similar to the barrel-stave model, but with the exception that the AMPs are permanently bound to the phospholipids in the membrane. Internal functions of AMPs may include DNA replication/translation inhibition, transcription inhibition and enzyme inhibition; (B) Many AMPs are also involved in immunoregulation. Some of these regulatory functions may include angiogenesis, cell proliferation, cytokine regulation, chemotaxis of certain leukocyte classes (including monocytes, lymphocytes and polymorphonuclear leukocytes or PMN), degranulation of mast cells, stimulation of phagocytosis and even modulation of gene expression.

Three main permeabilization models exist:

i Barrel-stave model: This model is used to describe the formation of pores in the lipid membrane. This is achieved through the amphipathic peptides that insert in a perpendicular orientation to the membrane and align so that the hydrophilic side chains point inward and form the transmembrane pore, while the hydrophobic side chains face outward and interact 
with the lipid bilayer $[10,60]$. This was the first model to be proposed as the mechanism of peptide induced pores [61]. AMPs that this model typically applies to are those that promote loss of electrochemical potential at low, well-defined peptide:phospholipid ratios [54]. The only AMP for which there is clear evidence of the barrel-stave mechanism is the non-ribosomally synthesised alamethicin (APD ID: AP02197), produced by the fungi Trichoderma viride [62].

ii Toroidal model: In this model, pores, consisting of peptides intercalated with lipids, are formed in the lipid membrane [63]. Amphipathic peptides accumulate parallel to the membrane surface, where their partial insertion causes the outer (but not the inner) leaflet to expand. The peptides re-orientate perpendicularly to the bilayer once a critical threshold is reached, thereby relieving tension. The bilayer undergoes a positive curvature and its thickness is modified, which creates transient pores consisting of both peptide and lipid molecules [54].

iii Carpet model: Partial membrane solubilisation in a detergent-like manner occurs with this model [54]. The amphipathic peptides accumulate parallel to the membrane via electrostatic interaction with anionic phospholipids - covering the membrane in a carpet-like fashion. When a threshold concentration is reached, detergent-like activity causes the formation of micelles and membrane pores [10].

It should be noted that although in vitro experiments have determined that some AMPs, for example magainin 2 (APD ID: AP00144) derived from the skin of the African clawed frog (Xenopus laevis), display cell selectivity towards microbial organisms without significant cytotoxicity towards mammalian cells $[64,65]$, most AMPs should be considered as displaying "partial selectivity". It is suggested that AMPs only display cell selectivity when placed in an actual situation where mammalian host cells are confronted with microbial organisms and that AMPs could potentially be toxic towards mammalian cells in the absence of microbial organisms. This fact is thought to be underestimated by current in vitro experimental procedures with regard to the volume of cells used for mammalian haemolysis (cytotoxic) vs. bacterial assays which does not give an accurate representation of the cytotoxic $v s$. the minimum inhibitory concentrations [26].

\subsubsection{Interaction of AMPs with Internal Targets}

Although the main mechanism by which AMPs appear to directly kill microbial organisms is through membrane permeabilization, some AMPs do not damage microbial membranes but still manage to kill or inhibit the growth of these organisms. Alternatively, some AMPs may cause disruption of the microbial membrane without leading to inhibition or death of the microbial organisms [66,67]. AMPs are therefore also believed to display direct killing action through the interaction with anionic intracellular targets such as DNA and RNA (Figure 2) $[25,68,69]$. These AMPs still have to gain access to their internal targets through the cell membrane and are believed to translocate over the cell membrane of the microbial organism without causing significant damage to the membrane, although the precise mechanism is still not fully understood, as highlighted by Nicolas [68]. AMPs are thought to exert their intracellular activity through inhibition of nucleic acid and protein synthesis, inhibition of enzymatic activity, and the inhibition of cell wall synthesis and cytoplasmic membrane septum formation $[25,69]$. 


\subsubsection{Modulation of the Immune System by AMPs}

Although the primary focus has been to identify AMPs with broad-spectrum antimicrobial activity through in vitro testing, many in vivo occurring AMPs have little direct antimicrobial activity [70]. The direct killing activities of some of these AMPs by either membrane perturbation or interaction with intracellular targets at physiological concentrations are antagonized by salt conditions, monovalent and divalent ions and serum [71,72]. Conversely, many of these peptides seem to be more involved in immunoregulation by acting as effectors of innate immune system. Some of these regulatory functions may include angiogenesis, cell proliferation, cytokine regulation, chemotaxis of certain leukocyte classes, degranulation of mast cells, stimulation of phagocytosis and even modulation of gene expression [70,73,74]. For example, human LL-37 has a pro-inflammatory action by up-regulation of specific chemokines (MCP-1 and IL-8) and binding to chemokine receptors such as IL-8RB, CCR, and CXCR-4 [75]. LL-37 receptors have been found in many different cell types, including monocytes, T-helper cells, mast cells, and epithelial cells, which suggest that certain AMPs can directly interact with host cells to induce immune responses [76,77]. However, it has also been shown that the induction of LL-37 has an in vitro anti-inflammatory function by inhibiting tumour necrosis factor $\alpha$ (TNF- $\alpha$ ) production in macrophages [78]. These types of AMPs can counteract pro-inflammatory responses by preventing lipopolysaccharides (LPS) from inducing TNF- $\alpha$ production, thus suppressing the expression of LPS regulated genes in macrophages [75]. Apart from this indirect suppression, the LL-37 peptides can also induce specific anti-inflammatory genes by directly influencing macrophage gene expression, preventing an overwhelming immune response which could lead to fatal sepsis or endotoxemia [75]. Consequently, it seems that certain AMPs serve a dual, and seemingly counterproductive, immunoregulatory function by stimulating both pro-inflammatory and anti-inflammatory responses. This dualistic action may be a symmetric feedback mechanism to battle infection while simultaneously managing the septic levels by supressing the expression of certain cytokines. It is becoming clear that AMPs are a vital component of the germ line encoded innate immune system.

\subsection{Therapeutic Potential and Obstacles Associated with AMPs}

Many AMPs are promising candidates for drug development. The major advantages these peptides offer compared to conventional antibiotics are that they have a broader spectrum of antimicrobial action [10]; they exert their activity at micromolar concentrations [5,79] and they have a limited probability of inducing pathogen resistance [80]. Although some AMPs, such as melittin, have low therapeutic potential because of their characteristic cytolytic activity, these natural AMPs can be used as templates to create peptide analogues with increased therapeutic efficacy. Structural analogues of melittin have proven to display similar or higher levels of antimicrobial activity with reduced toxicity [81-83]. Hybrid peptide formulations could also improve the antimicrobial activity and reduce toxicity $[84,85]$. AMPs also play a role in modulating the immunity (both the innate and adaptive immunity in higher organisms) and using these naturally occurring AMPs as templates to design novel drug candidates for the selective up-regulation of the innate immunity and suppression of pro-inflammatory cytokine response could prove to be effective anti-infective therapies [86]. One of the major limitations for the use of AMPs is that they are peptide based, which makes systemic use 
difficult, due to bioavailability issues. Therefore, most AMPs in clinical development are being considered for topical application [4,8]. However, the use of nano- and microparticles has been shown to be beneficial for the oral delivery of insulin [87,88]. In cancer therapy, the use of nanoparticles, containing melittin, has a higher affinity towards diseased cells over healthy host cells [89]. A study by Piras et al. showed that the use of nanoparticles loaded with temporin B (APD ID: AP00095), an AMP from the European common frog, Rana temporaria, increased the antibacterial activity and reduced cytotoxicity against mammalian cells [90]. The use of AMPs encapsulated in nanoparticles should therefore be further investigated regarding its potential use in the treatment of antimicrobial infections. AMPs can also be considered for multi-drug treatment regimens, as synergistic interactions were observed when antibiotic and AMP combinations were used against methicillin-resistant Staphylococcus aureus (MRSA) [91]. Finally, AMPs have a broader range of activity, as conventional antibiotics cannot be used for the treatment of viruses and are less effective against most parasites, while several AMPs have been shown to display antiviral and anti-parasitic activities [37,54,57].

\section{Neglected Tropical Diseases}

According to the World Health Organization (WHO), Neglected tropical diseases (NTDs) are a diverse group of 17 disabling, though neglected, conditions mostly affecting the world's poorest populations [1]. These diseases distress more than 1.4 billion people of low-income countries in Asia, Latin America and sub-Saharan Africa, causing more than 500,000 deaths annually [1,2]. In Africa alone, communicable diseases account for more than $70 \%$ of the total disease burden and deaths, with NTDs making up at least a fifth of this burden [92]. While these illnesses affect a considerable portion of the population, they may be considered "neglected" due to the dire lack of effective treatments and the fact that they are largely overlooked by funders and governing bodies (less than $5 \%$ of global health funding is allocated to alleviating the NTD burden) [3]. Although NTDs exist in the funding shadows of diseases like tuberculosis and HIV/AIDS, neglected diseases are noticeably contributing to the severity of the HIV pandemic by increasing the risk of horizontal and vertical HIV transmission [76,93,94]. While not all NTDs result in the loss of life, their morbidity and the accompanying economic loss are immense. NTDs can result in deformities and permanent damage, stunted growth, mental abnormalities and loss of eyesight and hence a lifetime of disability. The economic burden of NTDs are expressed as disability adjusted life years (DALYs), where each DALY unit refers to a healthy year lost due to premature death or disability [95]. The burden of NTDs amounts to staggering 46-57 million DALYs lost each year, second only to HIV/AIDS, with malaria and tuberculosis only coming in at third and fourth place, respectively [96].

The 17 NTD infections are caused by a wide variety of organisms including vector-borne protozoa (Trypanosoma and leishmaniosis), parasitic worms (helminths including Taenia solium, Echinococcus granulosus, Echinococcus multilocularis, Wuchereria bancrofti, Opisthorchis spp. Fasciola spp. and Paragonimus spp., Onchocerca volvulus and Schistosoma), bacteria (Mycobacterium ulcerans, Mycobacterium leprae, Treponema pallidum, Treponema carateum and Chlamydia trachomatis) and viruses (Flavivirus and Lyssavirus) [1]. Due to the initial lack of funding and the diverse nature of NTDs, research, diagnosis, prevention and treatment strategies are challenging. In late 2000, the international community committed itself to drastically reduce poverty and combat disease amongst 
poor populations of the world, known as the Millennium Development Goals. This action plan has brought much needed attention to the neglected diseases, leading to the establishment of the Global Network for Neglected Tropical Disease Control and a WHO department specifically tasked to address NTD related issues [3]. Despite all this positive progress, NTDs still cause massive global suffering in millions of people. Novel, cost-effective, rationally designed treatments are desperately needed to ease the burden of NTDs.

\subsection{Neglected Bacterial Infections}

The discovery of penicillin, the world's first antibiotic, by Alexander Fleming in 1928 was a major milestone in the treatment of bacterial infections. However, an ever-increasing rise in antibiotic resistance amongst bacterial species has led research into the development of new therapeutic agents for bacterial infections [97]. AMPs are promising candidates in this regard [4,5,98]. As mentioned earlier, AMPs neutralize bacteria through direct killing actions which involve membrane disruption and interaction with intracellular targets [67]. NTDs caused by bacterial infections include leprosy and trachoma. Both these diseases have debilitating consequences that remain even after the disease is cured, contributing to the socio-economic burden of these diseases. Current treatment regimens involve the use of antibiotics, and although these prove to be effective the occurrence of antibiotic resistance could affect therapeutic outcomes in the future. This section will focus on the potential use of AMPs for the treatment of leprosy and trachoma.

\subsubsection{AMPs against Mycobacterium Infections and Hansen’s Disease}

The mycobacterium genus includes pathogens that are known to cause serious infections in both humans and animals. Over 50 different mycobacterium species are known to be involved in human disease and most notably include Mycobacterium tuberculosis (causative agent of tuberculosis), M. leprae (leprosy) and M. ulcerans (Buruli ulcer) [6]. Mycobacteria are intracellular micro-organisms capable of infecting and replicating in host macrophages [99]. Due to the complexity and high lipid content of the mycobacterial membrane and emergence of multi-drug resistant strains, it is notoriously hard to effectively treat these infections [100]. Contributing to mycobacterium infections are the HIV/AIDS pandemic and the wide spread use of immuno-suppressive drugs [6]. Alternatives treatment strategies to conventional antibiotics may prove beneficial against this diverse genus of diseases.

Over the past two decades, numerous antimicrobial peptides, including LL-37, have been identified that offer direct and/or indirect antimicrobial activity against mycobacteria [101]. A large portion of the LL-37 peptide consists of hydrophobic amino acids, enabling this AMP to bind and disrupt the cell membrane of certain micro-organisms [46,102]. It has also been shown that during a mycobacterium infection, LL-37 is able to directly inhibit the host cell's response by interacting with TLRs [103]. This AMP also plays a crucial role in the innate immune response to mycobacterium infections in several cell types [101]. In summary, the AMP, LL-37, has the capacity to fortify specific host innate immune responses, in addition to directly eliminating mycobacteria and/or inhibit their growth. AMPs like these may enable the development of novel and innovative antibiotics based on natural host antimicrobial peptides. Several AMPs play a central role in immune activation and inflammation regulation, possibly providing a unique foundation for the development of novel therapeutic agents. 
"And if the priest sees that the scab has indeed spread on the skin, then the priest shall pronounce him unclean. It is leprosy." Leviticus 13:8.

References to leprosy (Hansen disease)-like symptoms date back millennia and can be found in ancient Egyptian writings and those of Hippocrates [104]. This chronic human disease is caused by the bacteria $M$. leprae and can have potentially debilitating neurological effects [105]. Although the implementation of global multi-drug therapy programs has considerably reduced the burden of leprosy, areas like Africa, Latin America and India still report more than 200,000 cases annually [106]. Until recently, the origins of leprosy could only be speculated on, with written records found in India (600 BC), China (500 BC) and even the armies of Alexander the Great likely referencing this disease between 327-325 BC [107]. Today, through comparative genomic studies, it has been deduced that leprosy spread from Africa to India, Europe and the Americas, mainly along colonisation, migration and slave trade routes [104]. There are four distinct and regionally specific M. leprae strains found globally, with strain 1 mainly found in Asia, East Africa and the Pacific; strain 2 is less predominant and is only found in regions of Malawi, Ethiopia, Nepal and New Caledonia; strain 3 is found in America, Europe and North Africa; and strain 4 is mainly predominant in the Caribbean and West Africa [104]. M. leprae has a genome of 3,268,203 base pairs (bp) that encodes for 1604 proteins [108], a genome that is considerably smaller than that of $M$. tuberculosis [109].

Gerhard Henrik Armauer Hansen (1841-1912) dedicated his entire career to studying leprosy and identified M. leprae as the causative agent of this disease in 1873 , which is also historically the first human-disease-causing bacterium to be identified [110]. Leprosy is a curable disease when treated with multi-drug therapy. Although it estimated that $95 \%$ of modern people have a natural immunity to leprosy, studies indicate that a small portion of the population is susceptible to this disease due to a defect in cell-mediated immunity [111]. In the 1940s, the sulfone drug, Promin (sodium glucosulfone) was introduced as the first effective treatment for leprosy and was replaced with dapsone (diaminodiphenyl sulfone) in the 1950s [112]. Nowadays, treatment consists of rifampicin and clofazimine once monthly while a dosage dapsone daily are used for treatment of patients with multi-bacillary infections over a period of 1 year [113]. Disadvantages of this modern treatment regimen include the long treatment periods and the looming prospect of antimicrobial resistance. Another major drawback, apart from understanding the complex clinical presentation of leprosy, is the lack of an appropriate experimental model.

AMPs appear to play an important role in the immune response to leprosy. The innate immune recognition of $M$. leprae seems to be mediated by the toll-like receptor 2 (TLR2) and mutations/ polymorphisms in TLR2 can affect host susceptibility to leprosy [114]. The cytokines interleukin (IL) 10 and 15 are also known to regulate macrophage functions in lesions [115]. The AMP, human $\beta$-defensin 3 (hBD3) (APD ID: AP00283), is also up-regulated during a leprosy type 1 reaction [106]. The induction of vitamin D dependant antimicrobial peptides LL-37, is one of the antimicrobial mechanisms employed by the host cell following phagocytosis [115]. In leprosy, LL-37 levels are relatively low due to the M. leprae mediated inhibition of the gene encoding for LL-37 (CAMP) [116]. This inhibition occurs through the up-regulation of the miRNA, has-mir-21, by M. leprae. Suppressing the translation of this miRNA, may lead to an improved innate immune response to M. leprae, enhancing the antimicrobial activity of LL-37. Another AMP involved in this disease is hepcidin (APD ID: AP00193). This defensin has a dual role as a hormone and antimicrobial peptide and plays a key part 
in hypoferremia of inflammation which increases the microbial resistance of host cells [117]. Hepcidin seems to be mainly up-regulated in multi-bacillary lesions, where it binds directly to the iron exporter efflux protein, ferroportin, resulting in its degradation [118]. By doing this, the host cell is limiting the circulating iron available to extracellular bacteria. Additionally, Stat3 is phosphorylated, which stimulates a downstream cytokine induced inflammatory response. Due to natural and artificial evolutionary pressures, pathogens, including $M$. leprae, are becoming antibiotic-resistant at alarming rates [119]. In order to combat the further emergence and spread of antibiotic resistance, new and innovative treatments strategies for microbial infections must be found. Pathogens are much less likely to successfully adapt their iron metabolic pathways to use alternative molecules after iron sequestration by AMPs.

\subsubsection{AMPs against Trachoma}

Trachoma is one of the oldest recorded diseases of mankind, and although it has been eradicated from the developed world, it is still prevalent in poverty-stricken, underdeveloped countries. Areas where trachoma is endemic are usually overcrowded, lacking in proper public health care facilities, sanitation and access to clean water [120]. The disease is most prevalent in Asia, Africa, the Middle East, Australia and Central and South America [121]. Trachoma is the leading cause of infectious blindness globally and is also referred to as the leading preventable cause of blindness worldwide [122]. Currently it is estimated that in the 51 endemic countries, trachoma is responsible for the visual impairment of 1.8 million people, of whom 500,000 are irreversibly blind, and approximately 232 million people living in trachoma-endemic areas are at risk of infection [121].

This infection is caused by the gram-negative obligate intracellular bacterium Chlamydia trachomatis. It has no known animal reservoir and infection is transmitted to the eyes through physical contact with the discharge from the nose and eyes of infected people or flies (Musca sorbens), acting as passive vectors [122]. The life cycle of $C$. trachomatis is unique compared to other bacteria due to its parasite-like dependence on a eukaryotic host cell to complete its replication cycle [123]. During this bacteria's life cycle, it adopts two distinct forms, the small extracellular elementary body (EB) and the larger intracellular reticulate body (RB). The EB is metabolically inactive and infectious, whereas the RB is metabolically active and represents the replicating form of $C$. trachomatis. The EB attaches to and enters host epithelial cells, transform into an RB, and exists inside inclusion bodies inside the host cell cytoplasm. The RBs use energy-rich metabolic intermediates from the host and undergo binary fission. Consequently, following the amplification of RBs, inclusions begin to take up a great part of the host cytoplasm and start to fuse. RBs differentiate back into EBs and are released through the lysis of host cells, infecting other cells $[120,124]$. The intracellular inclusions make it difficult for the immune system to eliminate the pathogen [120]. Two C. trachomatis biovars exist; trachoma to which serovars A-K are assigned and Lymphogranuloma venereum to which serovars L1, L2, L2a and L3 are assigned [125]. Serovars A, B, Ba and C in the trachoma biovar cause trachoma and serovars D-K are responsible for sexually transmitted genital tract infections [124]. Sexually transmitted C. trachomatis infections may be implicated in ocular trachoma infections in children [126].

The SAFE program for the treatment and management of trachoma has been established by the WHO [127], where the acronym SAFE represents: Surgery for trachomatous trichiasis, Antibiotics for active disease, Facial cleanliness to reduce transmission and Environmental improvements. Traditionally, 
antibiotic treatment consists of the use of $1 \%$ topical tetracycline ointment on both eyes twice daily for six weeks or a single oral dose of azithromycin. The treatment with azithromycin is favoured, as it has the potential to be used for mass community based treatment in endemic regions and displays higher patient compliance and effectiveness [128,129]. Much progress is being made in achieving the goal set by the WHO to eliminate blinding trachoma globally by 2020 , with the disease being eradicated in some countries [121]. However, due to persistent infections and therefore antibiotic treatment, antibiotic resistance may become an issue. Therefore, alternative treatment strategies need to be investigated.

AMPs have been investigated for the use of the treatment of $C$. trachomatis infections. A study performed by Donati et al. showed that in vitro SMAP-29 (APD ID: AP00155), an $\alpha$-helical cathelicidin from sheep (Ovis aries), was able to reduce the inclusion number for 10 strains of $C$. trachomatis (including serovars A, D, E, H and I). The integrity of EBs was also compromised [130]. Although, the direct therapeutic use of SMAP-29 is problematic because of its cytotoxic and hemolytic activity towards mammalian cells, this study indicates that SMAP-29 could be a useful compound in the development of anti-chlamydial drugs using this natural peptide as a template and making analogues with higher specificity and lower toxicity [131]. Another approach, which may be considered instead of the direct application of these peptides, is AMP gene therapy [132]. This approach uses recombinant plasmid vectors to express AMPs, which may potentially be cytotoxic to healthy host cells, in a controlled manner in infected cells. Studies performed by Lazarev et al. [133-135] demonstrated the potential use of AMP gene therapy for the treatment of $C$. trachomatis-infected cells. An in vitro study by Lazarev and colleagues showed that the introduction of recombinant plasmid vectors expressing the melittin gene, under the strict control of an inducible promoter, showed inhibition of C. trachomatis in infected cells. The mechanism by which the bacterial growth was inhibited was suggested to be through direct cytotoxic effect of melittin on the bacteria. It was also shown that the transmembrane potential of the transfected cells was lowered, which could disrupt the adhesion of the bacteria to the cell and hinder the normal process of intracellular development [133]. In a subsequent in vivo study by Lazarev et al., melittin was produced in the genital tract of mice infected with C. trachomatis, using the plasmid vector system. The majority of the melittin-protected mice were free of the pathogen after 27 days [135]. In a later in vitro study performed by the same group, the anti-chlamydial activity of the recombinant plasmid vector encoding cyto-insectotoxin 1a (CIT 1a, APD ID: AP02163), a linear cytolytic AMP found in the venom of the central Asian ant spider, Lachesana tarabaevi, was investigated [134]. This study concluded that CIT 1a was an attractive candidate for targeting intracellular pathogens, as C. trachomatis infection was inhibited in the early stages of its life cycle, with a higher efficacy than had previously been reported for melittin [133] and with a negligible effect on cell viability. The effect of the direct expression of melittin in infected cells on cell viability was, however, not reported for the previous two studies. Based on these results, CIT 1a can be considered a potential agent for gene therapy for C. trachomatis infections.

\subsection{Neglected Protozoan Infections}

All protozoa are unicellular eukaryotic organisms with a trophozoite stage and a resistant cyst form. Medically important phyla include apicomplexa, such as Plasmodium and Toxoplasma, sarcomastigophora such as Trypanosoma and ciliophora such as Trichomonas. The pathogenicity of protozoa is not well 
understood, but in general they have fewer pathogenic mechanisms than bacteria. They have the distinct advantage of being able to avoid host defences by several mechanisms. Transmission of protozoa to humans occurs through the faecal-oral route or through a vector [136,137]. Neglected diseases caused by protozoa include chagas disease, human African trypanosomiasis and leishmaniosis. Most of these protozoan diseases have enormous impact on human health and cause great economic and social burdens [138]. The typical protozoan infections are appealing targets for AMPs, as the molecules can be targeted to stages in the invertebrate vector or the vertebrate host. There are excellent reviews on the possibility of using AMPs as new chemotherapeutic options for malaria, chagas disease and sleeping sickness, as well as leishmaniosis [34,139]. This section will focus on the potential use of AMPs for the treatment of the neglected diseases chagas disease, sleeping sickness, leishmaniosis and malaria.

\subsubsection{AMPs against Chagas Disease}

Chagas disease, or American trypanosomiasis, is caused by the parasite Trypanosoma cruzi. The disease was initially confined to South America, but 2010 epidemiological data include North-America, Europe, Australia and Japan as sites of T. cruzi infection [136,137,140]. The parasite is spread by the triatomine bug (part of the diverse Reduviidae family), which infects the human host when feeding, and it is also spread by travellers, organ transplants, blood transfusions, contaminated soil, food or water and by mother to infant transmission. The parasite has a complex life cycle including a trypomastigote in human blood and the epimastigote in the vector [140]. The clinical presentation occurs in two phases: an acute phase that lasts about two months after initial infection, and a chronic phase that can last for years. The acute infection is often misdiagnosed or unrecognized. However, treatment is most effective when initiated during the acute phase. From the intermediate phase, which is characterised by patients with chronic infection without clinical symptoms, $20 \%-30 \%$ of patients progress to a more serious chronic stage with chronic inflammation of the heart or digestive muscles [141]. There are only two drugs available for the treatment of chagas disease, benznidazole and nifurtimox. Both of these drugs are highly effective if administrated during the acute phase, but the efficacy declines with prolonged infection. Additionally, these drugs are toxic with negative side effects and are not effective in the chronic stage of infection [138,142,143]. There is a dire need for alternatives and AMPs from natural compounds seem to be an attractive option.

Several studies have reported promising effects of crude venom extracts containing AMPs from various sources against protozoan parasites. The crude venom of Apes mellifera was shown to decrease the viability and alter the ultrastructure of all T. cruzi developmental forms. This venom was also shown to be selective towards the parasite with no toxicity in mammalian cells at the tested concentrations [144]. In a follow up study by the same group, the AMP melittin from the venom of A. mellifera was used to prove that the peptide induced morphological alterations in the different developmental forms of the parasite, which could be characterized as apoptosis and autophagy. They also provided evidence that melittin could be used in concentrations up to $1 \mu \mathrm{g} / \mathrm{mL}$ to treat infected host cells [145]. Another group investigated the efficacy of the antimicrobial peptides apidaecin 14 and melittin from $\mathrm{A}$. mellifera, penaeidin (APD ID: AP00392) from the black tiger shrimp (Penaeus monodon), cecropin A (APD ID: AP00139) from the silk moth Hyalophora cecropia, moricin (APD ID: AP00147) from the silk worm Bombyx mori and magainin 2 produced by the African clawed frog (Xenopus laevis). Cecropin A, 
magainin 2, apidaecin and melittin were able to kill $T$. cruzi. These peptides were also investigated in combinations for synergistic effects, and in each case the addition of a second AMP increased toxicity [146]. Previously synthetic analogues of magainin 2, namely magainin B, G and H, were evaluated against $T$. cruzi. Only magainin B and G were effective against the parasite [147]. Synthetic derivatives of cecropin B were active against T. cruzi, where Shiva-1 the peptide with only $40 \%$ homology was most effective at killing promastigotes [148].

Dermaseptins and phylloseptins are cutaneous secretions of the tree frog Phyllomedusa genus. Dermasiptin-01 (APD ID: AP01389) from Phyllomedusa oreades showed significant lytic activity against T. cruzi with minimal activity against erythrocytes [149]. Dermaseptins form Phyllomedusa nordestina was investigated by another group. Dermaseptin 1 and 4 and phylloseptin- 7 and 8 were effective against T. cruzi at micromolar concentrations. Dermaseptin 1 and 4 and phylloseptin 8 were also non-toxic to macrophages [150]. AMPs from various aquatic animals were also evaluated against T. cruzi promastigotes. Only tachyplesin I (APD ID: AP00214) from the horseshoe crab Tachypleus tridentatus was able to kill T. cruzi epi- and promastigotes at micromolar concentrations. Tachyplesin I was, however, hemolytic at high concentrations [151].

\subsubsection{AMP against Human African Trypanosomiasis}

Human African trypanosomiasis is a parasitic disease mainly caused by two subspecies, Trypanosoma brucei gambiense and T. brucei rhodesiense, and causes chronic sleeping sickness in sub-Saharan African countries [136]. The clinical presentation of the disease is complex, making diagnostics challenging and treatment difficult [137]. The life cycle is similar to chagas disease with a trypomastigote phase in the human reservoir; however the epimastigote exists in the tsetse fly vector. Due to parenteral administration and severe toxicity associated with current chemotherapy options increasing incidence of treatment failure is observed [152]. The drugs used in the treatment depend on the infecting species as well as the stage of infection. Pentamidine and suramin is used in the first stage, and although effective, suramin has severe side effects. Second stage treatment includes IV melarsoprol, eflornithine and a combination of nifurtimox and eflornithine [153,154]. In comparison with the other parasitic infections, relatively few AMPs have been identified or evaluated for efficacy against T. brucei.

Temporin-SHd (APD ID: AP02118) from the North-African frog Pelophylax saharicus had significant growth inhibitory activity against T. brucei and T. cruzi [155]. Mammalian AMPs including $\alpha$-defensins, $\beta$-defensins and cathelicidins have proved successful against $T$. brucei. In vivo administration of cathelicidins to mice infected with $T$. brucei significantly reduced parasitemia [156]. In another study the bovine cathelicidin BMAP-27 (APD ID: AP00366) from Bos taurus (bovine) and its derivative BMAP-18 inhibited both life cycles of $T$. brucei at low micromolar concentrations. BMAP-18 induced apoptosis-like cell death, but necrosis was induced at higher concentrations [157].

\subsubsection{AMPs against Leishmaniosis}

Leishmaniosis species causes serious disease in humans. The typical infection is cutaneous, although visceral (kala-azar) and mucocutaneous leishmaniasis also exist. Visceral leishmaniasis caused by Leishmania donovani is fatal if left untreated. Cutaneous leishmaniasis caused by L. major, 
L. tropica, L. mexicana and L. panamensis frequently occurs every 3 to 18 months and leaves disfiguring scars [136,158]. Leishmania have a simple life cycle with only an amastigote in mammalian cells and promastigote in the insect (sand fly) [137]. The current chemotherapy available includes pentavalent antimonials sodium stibogluconate and meglumine antimoniate, amphotericin B and its lipid formulation AmBisome ${ }^{\circledR}$ (amphotericin B) and pentamidine. Antimonials remain effective for some forms of leishmaniasis, but the drugs' usefulness is limited by the required parenteral administration for 28 days and the emergence of significant resistance. The use of pentamidine is limited due to its toxicity [159]. Several AMPs have been evaluated against Leishmania and some promising candidates have been identified.

Temporins, isolated from the European common frog, Rana temporaria, represent natural peptides with high anti-leishmanial activity. One of the first studies to prove the anti-leishmanial activity of temporins investigated temporin A (APD ID: AP00094) and B (APD ID: AP00095) against L. donovani promastigotes and L. pifanoi amastigotes. They found that both temporin A and B were active against the insect and mammalian stages at $15-25 \mu \mathrm{M}$ concentrations [160]. Chadbourne et al. investigated the potential use of temporins against L. mexicana insect stage promastigotes and the mammalian stage amastigotes. The temporins investigated included temporins A, B and $1 \mathrm{Sa}$. These AMPs showed no significant activity against $L$. mexicana amastigotes, but significant anti-leishmanial activity was observed against promastigotes with temporin A [161]. Temporin-1Sa (APD ID: AP00898) isolated from the North-African frog, Pelophylax (Rana) saharica, had significant activity against the promastigote and amastigote stages of $L$. infantum at a concentration that was not harmful to macrophages [162]. In another study temporin-Shd had similar activity against several species of Leishmania promastigotes and amastigotes [155]. Temporins A, B, 1Sa, F (APD ID: AP00098) and L (APD ID: AP00101) were effective against L. mexicana promastigotes, but the amastigotes were resistant to all temporins tested. The resistance was attributed to the lack of proteophosphoglycan and anionic charge in the membrane of the amastigotes [163]. The proposed mechanisms of action whereby they function include rapid disruption of plasma membrane potential and decrease in intracellular ATP levels [160].

Dermaseptin S4 (APD ID: AP00160) from the South-American Sauvages leaf frog (Phyllomedusa sauvagii) and its synthetic analogues induced potent lysis for L. major promastigotes. Positive or negative mono-substitutions in the synthetic peptides did not significantly affect the antileishmanial activity [51]. Dermaseptin 01 was shown to be active against L. infantum promastigotes by membrane damage and flagella alterations [164]. Dermaseptin from Phyllomedusa hypochondrialis (DShypo 01) was evaluated against $L$. amazonensis. It proved more effective at killing promastigotes than dermaseptin 01, and was not toxic to white blood cells or erythrocytes [165].

Other AMPs from various organisms active against Leishmania include gomesin (APD ID: AP00191) from the tarantula spider Acanthoscurria gomesiana, indolicidin and plant derived thionins. Gomesin decreased the viability of L. amazonensis promastigotes with little activity against human erythrocytes [166]. Indolicidin and two peptides derived from seminalplasmin exhibited significant anti-leishmanial activity. Additional to the membrane effects these peptides were also able to induce autophagy in L. donovani [167]. Different isoforms of thionins from common wheat (Triticum aestivum) were tested against $L$. donovani promastigotes. These thionins proved effective in the low micromolar range and membrane permeability was found to be an essential step in the lethal mechanism [168]. 
Also, synthetic cecropin A, andropin and dermaseptin were found to be active against L. major and L. panamensis. These three synthetic peptides have higher therapeutic potential were also highly selective with low toxicity against human erythrocytes and dendritic cells [169]. Pexiganan (Locilex ${ }^{\circledR}$ ), a synthetic magainin-based lysine-rich peptide, which is undergoing phase 3 clinical trials for diabetic foot ulcers [4], induces apoptosis in Leishmania promastigotes. Activity is favourable if the strain of Leishmania is surface protease-deficient [170,171]. However, an arginine-rich variant of pexiganan proved to be protease resistant and displayed enhanced activity against wild type Leishmania in vitro [172]. These studies provide valuable insights into the use of AMPs against parasitic infections

\subsubsection{AMPs against Malaria}

Malaria is an infectious disease caused by parasites of the Plasmodium genus. This life-threatening disease is responsible for 219 million new cases and 660,000 deaths annually, making it one of the deadliest modern infections [173]. These parasites are primarily hosted by female Anopheles mosquitoes, which act as vectors transmitting the protozoan organisms to humans when feeding. There are four known species that infect humans: Plasmodium falciparum, $P$. vivax, $P$. ovale and $P$. malariae, though $P$. falciparum causes the majority of malaria infections [136,173]. The parasite has a complex life cycle with an asexual cycle in the human host and a sexual cycle in the mosquito. The asexual cycle includes ring and trophozoite stages in red blood cells, which are targets for chemotherapy. The sexual stage in the mosquito includes gametocytes and sporozoites, which are transmitted to humans [137]. Clinically, the disease presents initially with flu-like symptoms, which may be difficult to recognise as malaria. If left untreated, within the first $24 \mathrm{~h} P$. falciparum malaria may progress to a more severe illness. Chemotherapy, when initiated early, is successful, but increasing resistance to current treatment options is proving problematic [174]. Additionally, many antimalarial drugs are toxic in high doses, though Pheroid vesicles have been shown to reduce toxicity [175]. Various AMPs have been investigated as a possible new class of antimicrobial drugs. A very thorough review on this topic was recently published [34], though only selected examples will be highlighted in this section.

The hemolytic dermaseptin S4 was shown to have antimalarial activity against $P$. falciparum (FCR3 strain). The peptide causes significant lysis of the ring and trophozoite stages of the parasite [176]. Natural peptides melittin and transportan 10 (TP10), mastoparan X (APD ID: AP02355) and anoplin (APD ID: AP00447) from the Vespula lewisii wasp, were effective against Plasmodium sporogenic stages and were considered to block transmission [177]. Synthetic analogues of cecropin B, SB-37 and shiva-1 were effective at limiting the growth of different stages of P. falciparum [148].

Gomesin was evaluated against $P$. falciparum and $P$. berghei. This AMP inhibited chloroquine-sensitive (3D7) and chloroquine-resistant (W2) parasites, but only at micromolar levels, compared to nanomolar levels of artesunate. Gomesin was more effective against $P$. berghei mature gametocytes and also proved successful as a transmission blocking agent [178]. These examples of AMPs all act against different life cycles of the parasite, with different mechanisms of action. At this stage the most promising candidates in AMPs for malaria seems to be those that are involved in transmission-blocking. However, this is still a developing field and many of the AMPs active against other parasites have not been evaluated in malaria models. 


\subsection{Neglected Helminth-Related Infections}

Helminths, also known as parasitic worms [179], are a group of evolutionary unrelated organisms that can be divided into two major groups, namely the Platyhelminthes (flatworms) and Nematoda (roundworms) [180,181]. Worldwide, more than 2 billion people are infected with one or more of these parasitic worms, including the hookworm, Necator americanus; the roundworm, Ascaris lumbricoides; and Ancylostoma duodenale; and the whipworm, Trichuris trichiura [182]. Although these parasitic infections primarily affect underdeveloped populations with insufficient sanitation, housing, water supplies and primary health care systems [183,184], they are also widespread in developed countries [185].

Presently, the treatments for helminth infection are parasite-specific and involve regular administration of anti-parasitic drugs. Although these treatments (including benzimidazoles for hookworm infections and praziquantel for schistosomiasis infections) are currently effective, parasite re-infections are still a problem and helminths will most likely develop resistance to these drugs [186]. Consequently, investigations into novel helminth-specific treatments should seriously be considered. There are currently eight helminth infections identified by the WHO as NTDs. This section will focus on the potential use of AMPs for the treatment of taeniasis, cysticercosis and onchocerciasis.

\subsubsection{Possible AMPs against Taeniasis and Cysticercosis}

Taeniasis is a parasitic intestinal infection caused by two species of adult tapeworms, namely Taenia solium (pork tapeworm) and Taenia saginata (beef tapeworm). This parasitic disease is contracted when humans ingest raw or underprepared beef (infected with T. saginata) or pork (T. solium). The accidental consumption of T. solium eggs, through contaminated food or water, can lead to cysticercosis [187]. The eggs move into the digestive tract, where they hatch and develop into larvae (cysticerci). These larvae can then enter the circulation and invade host tissue and organs, such as muscles, eyes, skin and the central nervous system. If the cysticerci spread to the brain, neurocysticercosis may develop, which can be a fatal condition [188]. Symptoms include blindness, headache, dementia, meningitis and epilepsy. Current treatment of taeniasis includes praziquantel or niclosamide [189]. Treatment of neurocysticercosis includes long courses with praziquantel or albendazole, and also supporting therapy with anti-epileptic drugs and corticosteroids [190]. There are, however, drawbacks involved when using these drugs. Praziquantel can induce epileptic seizures in patients with neurocysticercosis, whereas niclosamide is only effective against adult intestinal tapeworms [187,191].

Temporin A and iseganan IB-367 (a protegrin-1 (APD ID: AP00195) derivative that belongs to the cathelicidins family) have anti-parasitic effects against $T$. crassiceps [192], a parasite which has a close relationship with $T$. solium. Iseganan IB-367 functions by disrupting cell membranes through the induction of pores. Both these peptides reduce the parasitic load and damage the tegumentary surface of the cysticerci. In a study by Landa et al., temporin A reduced the parasitic load by 50\% and iseganan IB-367 by about $25 \%$. These peptides also induced morphological changes in vitro in the cysticerci [193]. AMPs have therefore been shown to be effective in destroying cysticerci and damaging the wall of the cysticerci, which is critical for the death of the cestode. These, or structurally similar peptides, should 
be investigated as alternatives to current anthelminthic treatment to bolster the treatment of taeniasis and cysticercosis.

\subsubsection{AMPs from Onchocerciasis}

Onchocerciasis, also known as "river blindness", is caused by the filarial worm Onchocerca volvulus [194], the second most common cause of blindness from infection after trachoma [195]. The disease is transmitted by the bites of infected blackflies (Simulium species) which breed in fast flowing streams and rivers, predominantly in central Africa [196]. The adult worms produce microfilariae in the human body where it migrates to the eyes, skin and other organs. Symptoms develop as a result of the microfilariae moving around in the body and inducing inflammatory responses. Severe itching, skin lesions and nodules under the skin are some of the symptoms that infected people develop. Eye lesions can also develop, causing visual impairment ultimately leading to permanent blindness. The recommended treatment for this disease includes ivermectin once yearly for 10 to 15 years [194]. Repeated doses of ivermectin over several years are required for the elimination of an onchocerciasis infection to halt the transmission of the parasite in the long term [197].

Human neutrophil peptide 1-3 (HNP1-3) was identified in O. volvulus worms extracts [198]. Human neutrophil peptides are $\alpha$-defensins that belong to the family of cationic trisulfide-comprising antimicrobial peptides [199]. HNP1-3 has been shown to mediate the macrophage response to micro-organisms by stimulating the release of IFN- $\gamma$ and TNF- $\alpha$ [200]. Defensins can neutralize a target micro-organism by binding and permeabilizing its membrane. Although human neutrophil peptides can still bind to the surface of $O$. volvulus, this parasitic worm may have developed a limited resistance to these AMPs through co-evolution. This may explain why human neutrophil peptides were isolated with $O$. volvulus worm extracts, as the peptides are able to bind to the surface of the worm but not cause permeabilization and death. Identifying and/or investigating natural AMP homologs of human neutrophil peptides may yield alternative treatments for onchocerciasis.

In another study, Eberle et al. identified at least three excretory/secretory products (including galectin) of $O$. ochengi and $O$. volvulus with significant antibacterial activity against $E$. coli [11]. The excretory/secretory peptides of many parasites are similar to host defence peptides and, as mentioned earlier, host defence peptides have been shown to have antibacterial, antifungal, anti-parasitic and antiviral activities [201]. The peptides excreted/secreted by $O$. ochengi and $O$. volvulus present a promising pool of potential novel AMPs and further investigation into these peptides is needed [11].

\subsection{Antiviral Peptides and Their Potential Use to Treat Viral Diseases and Possible Application to Viral Neglected Tropical Diseases}

Viral diseases are one of the leading causes of morbidity and mortality globally, especially in lower income countries. Adding to this problem, antiviral treatments are expensive to develop and are usually only effective against a single virus [202]. The control of viral diseases has always been a challenge, due to their genetic diversity, short and effective replication cycles, diverse transmission means, and adaptability, as well as the wide variety of hosts. In their history, the US Food and Drug Administration (FDA) has only approved about 60 antiviral drugs for seven viruses (cytomegalovirus, herpes simplex virus, hepatitis B and C viruses, human immunodeficiency virus-1 (HIV-1), influenza, 
and varicella-zoster virus) and almost half of the approved antiviral drugs are for HIV-1 [203]. Despite this, a considerable amount of peptides have been shown to be effective against wide range of viral infections [204-208]. There seem to be two main antiviral mechanisms of AMPs as reviewed in Klotman and Chang [57]. The first mechanism is similar to the antibacterial activity of AMPs and involves direct disruption of viral envelopes or interaction with internal viral targets, while the second is thought to be an indirect antiviral action by stimulating specific innate immune mechanisms of the infected host cell.

When the first antiviral AMP (HNP-1) was discovered in 1986, it was believed that these peptides only had a direct effect on enveloped viruses while overlooking non-enveloped viruses [209]. HNP-1 was reported to have a direct inhibitory effect on the enveloped viruses such as herpes simplex virus-1 and 2, influenza virus and vesicular stomatitis [209]. It is hypothesised that the method of direct inactivation is the disruption of the viral capsid or preventing host entry by binding to the viral glycoproteins [57], but the exact mechanism is not clear and requires further investigation. AMPs (including HNP-3 and human $\beta$-defensin-3) have no detectable direct effect on the non-enveloped rhino-, echo- and reoviruses [209,210]. However, it has been shown that the AMPs HNP-1 and $\beta$-defensin-3 can stimulate infected host cells to subdue the viral replication of non-enveloped viruses after virion entry [211]. Instead of blocking the binding of the virus to the host cell and subsequent endocytosis, antiviral peptides may obstruct the release of the virion from the endosomes. Still, further studies are needed to elucidate the mechanisms by which AMPs can suppress non-enveloped viral replication.

In a study done by Carriel-Gomes et al., they evaluated the in vitro antiviral activity of nine AMPs against the human adenovirus (respiratory strain), type 1 herpes simplex virus and rotavirus (SA11 strain) [212]. Although several AMPs tested showed promising antiviral activity, most peptides were cytotoxic at their active concentrations. However, modifying the peptide structures of these AMPs may reduce their cytotoxicity and make them attractive antiviral treatments. In order for the cell to mount an effective antiviral offensive, most viral infections lead to the stimulation of a complex cascade of host cell signalling pathways (including Jak-STAT- and Toll pathways), ultimately resulting in the expression of IFN-stimulated genes (ISGs), which is able to directly inhibit viral replication [213-215]. The secretion of cytokines belonging to the interferon (IFN) family (IFN type I and III in particular), play an important role in this innate immune response by activating the expression of IFN-stimulated genes (ISGs) [216,217]. Many AMPs have been shown to exhibit antiviral activity during several phases of viral pathogenesis [218] and several AMPs play a central role in immune activation and inflammation regulation [77,219], possibly providing a unique foundation for the development of novel therapeutic agents. This section will focus on the potential use of AMPs for the treatment of dengue viral disease and rabies.

\subsubsection{AMPs against Dengue Viral Disease}

Dengue viral disease is a mosquito (Aedes aegypti)-borne pathogen predominant in tropical and sub-tropical regions, putting more than 3.6 billion humans at risk of infection [220,221]. This disease is caused by one or more of five serotypes of the dengue virus (DEN-1 to -5) belonging to the genus Flavivirus [222,223]. Genetically, at least four of the five dengue virus serotypes seem to share 
a common ancestor in sub-human primates from central and east Africa [224]. The modern dengue virus is an enveloped, single positive-stranded RNA virus with a genome of $\sim 11,000$ bp that codes for three structural proteins and seven non-structural proteins [225]. Phylogenetic analysis indicated that dengue viruses have exceptionally high mutation rates (as high as 1 nucleotide mutation per life cycle), which is most likely due to the lack of proofreading ability in their RNA-dependant RNA-polymerase [226,227]. Only the female mosquitos act as vectors for the dengue virus and they are infectious throughout their entire lifespan [228]. Alarmingly, there has been a rapid ecological expansion of the virus's vector, A. aegypti, over the past few decades, dramatically increasing the risk of human infection [221]. Dengue virus infects approximately 500 million people across 124 countries annually. The resulting infection causes nearly 21,000 deaths and an economic burden of more than US \$950 million each year $[220,229,230]$. The majority of mortalities are caused when dengue viral disease progresses to severe dengue haemorrhagic fever (DHF) or dengue shock syndrome (DSS) [220]. Due to the five diverse dengue virus serotypes, high mutation rate and lack of a working animal model, no effective vaccine exists for this virus [231]. Additionally, disease prevention is impractical due to difficult vector control, and clinical treatment is limited to secondary shock prevention care. There is a dire need for the development of alternative anti-dengue viral treatments.

As an alternative approach, Rothan and colleagues investigated the potential of the AMP latarcin (Ltc-1; APD ID: AP01010) from the venom of the ant spider Lachesana tarabaevi to inhibit the replication of dengue viruses in cultured Vero cells [232,233]. In dengue virus, Rothan et al. showed that the Ltc-1 peptide binds to the non-structural protein 3 (NS3) which may inhibit substrate binding to the NS3 active site, hindering the formation of the NS2B co-factor active site [233]. For the release of the mature dengue viral structural and non-structural proteins, the NS2B-NS3pro complex must first cleave the dengue viral poly-protein at specific sites [234,235]. Consequently, the Ltc-1 inhibition of the NS2B-NS3pro complex can halt virus replication by hindering the post-translational function of the dengue viral poly-protein [233,236].

In another study, two synthetic AMPs designed to target the domain III of the dengue DENV-2 E protein significantly inhibited virus entry in to LLC-MK2 cultured cells [237]. Efficient entry of the virus particle into the host cell is crucial to the success of any infection. In the case of the dengue virus, attachment to the host cell surface receptors and subsequent viral-cell membrane fusion is mediated by the virus's E protein [238]. The E protein consists of three domains comprising domain I (the central structural domain), domain II (the dimerization domain) and domain III (the receptor-binding domain) [239]. Apart from cell entry, the E protein is also the chief target for protective antibodies against the dengue virus, and there are several conserved regions between the dengue serotypes [238]. The two synthetic AMPs designed by Alhoot and colleagues targeted a short amino acid sequence in the lateral loop of domain III in strain 2 of the dengue virus. This may reduce the viral load during early infection and buy time for an effective immune response which can reduce the severity of infection. This inhibitory function of these synthetic AMPs against dengue virus can provide a basis for identifying similar natural AMPs to develop new therapeutic strategies against dengue infections. 


\subsubsection{AMPs against Rabies}

Rabies has an exceptionally high fatality rate for an infectious disease (fatality rate of virtually $100 \%$ after symptoms appear) and is responsible for an estimated 55,000 deaths annually [240]. However, due to underreporting, deaths may be as much as 100 times higher [241]. This zoonotic disease has been plaguing mankind for more than 5000 years and has a very unique and wide range of hosts for a viral disease, as it can infect almost all warm-bodied animals [242,243]. Rabies mainly affects the poor, rural communities of developing regions and is $100 \%$ vaccine preventable. The causative agent of rabies is the enveloped, negative-sensed, single-stranded RNA Lyssavirus (Lyssa, Greek goddess of madness and frenzy) from the Rhabdoviridae family [244]. The Lyssavirus genome consists of approximately $12,000 \mathrm{bp}$ and encodes for 5 viral proteins. The virus is found in the saliva of infected animals and is usually transmitted through their bites. The rabies virus can supress the host's innate immune response by subduing the type I interferon response [245]. After the initial wound entry, Lyssavirus uses the central nervous system to invade the host's neurons, where it replicates and spreads [246]. Symptoms of the classical rabies infection commonly include hydrophobia, muscle spasms, extreme aggression (erratically attacking objects or other humans) and terror [242,247]. Nowadays, rabies infections are primarily controlled by limiting animal infections. In the United States, if a human is exposed to a rabies-infected animal, a prophylaxis containing rabies immunoglobulin together with an inactivated rabies virus vaccine is administered [248]. With the approval of the WHO, viral vector vaccines and DNA vaccines have been introduced in developing countries to reduce vaccination costs $[249,250]$. Pre-exposure rabies vaccines exist, but are not widely used and mainly reserved for individuals that have a high risk of infection, including researchers and veterinarians due to their high costs [251].

In a study by Real et al., short, natural peptides that target rabies viruses were evaluated for their antiviral potential [252]. They proposed an antiviral drug discovery strategy based on the mimicry of natural peptides such as the lebocin 1 and 2 (APD ID: AP00359) from silkworms (Bombyx mori) and $\mu$-conotoxin from cone snails (Conus geographus). A large amount of peptides were screened for their binding affinity to the phosphoprotein of the rabies virus. The viral phosphoprotein plays an important role in the transcription-replication complex and reduces non-specific RNA binding by acting as a chaperone for the nucleoprotein $[253,254]$. Only selected peptides with high binding affinity were then evaluated for their antiviral potential against rabies viruses. After an ex vivo inhibition of viral replication assay, they identified four structurally diverse peptides (C2, C6, C8 and P16) that exhibited strong rabies virus inhibitory properties [252,255]. Three of the four AMPs (C6, C8 and P16) had an algorithmically predicted $\alpha$-helical conformation, while the AMP with highest antiviral activity, C2, seemed not to possess a helical-like structure. The central role that the viral phosphoprotein plays in the transcription-replication complex makes this protein an attractive target for antiviral treatments. Real et al. showed that AMPs based on natural peptides can be used to drastically inhibit the replication of rabies viruses. Their work also offers an alternative strategy for identifying novel antiviral peptides, with the objective to develop new types of antiviral treatments. Besides this study, very little published work is available on the antiviral treatments for rabies. There have, however, been some AMPs identified for other viruses in the Rhabdovirus family, including casein and $\alpha_{\mathrm{s} 2}$-casein, which can drastically inhibit the replication of the infectious haematopoietic necrosis virus in salmonid fish [256]. 
Another study also found that human $\alpha$-defensin-1 has antiviral activity against the haemorrhagic septicaemia virus [257]. All these findings suggest that AMPs are a viable antiviral treatment option for viruses in the Rhabdovirus family, and more efforts should be made to identify and investigate these peptides as possible rabies treatments.

\section{Conclusions}

NTDs are a diverse group of 17 disabling, though neglected, conditions affecting a fifth of the world's population, resulting in more than 500,000 deaths annually. These infections, prioritized by the WHO, are caused by a wide variety of organisms including vector-borne protozoa, parasitic worms, bacteria and viruses. Due to the diverse nature of NTDs and the initial lack of funding, research, diagnosis, prevention and treatment strategies are challenging. The Millennium Development Framework is a United Nations-led coalition for the alleviation of poverty in the developing regions of the world by 2015. One of the goals of this framework is to combat HIV/AIDS, malaria and Neglected tropical diseases. Although this goal has brought much-needed attention to neglected diseases, NTDs still cause massive global suffering in millions of people. Innovative, cost-effective, rationally designed treatments are desperately needed to ease the burden of NTDs.

Due to the ever-increasing rise in antibiotic resistance, there is a dire need for the development of alternative treatment strategies. AMPs, produced by all known living species, may be considered natural antibiotics due to their central role in the innate immune system, providing the first line of defence against microbial infections. These peptides have a broad range of activity against bacteria, parasites and viruses. Numerous studies have focused on the potential use of AMPs for the treatment of NTDs, as summarised in Table 2. Many of these AMPs have shown to be promising candidates for the development of therapeutic agents in the battle against NTD infections. However, many obstacles still need to be overcome, including the cytotoxic effects of some peptides and challenges regarding bio-availability. Structural analogues of natural AMPs and hybrid peptide formulations have shown promising results in lowering cytotoxicity and should therefore be further investigated for the possible treatment of NTDs. Additionally, bio-availability issues may be overcome by utilizing nano- or mircoparticle formulations which can also increase specificity and decrease toxicity associated with some AMPs. Apart from the direct application of AMPs, they may be considered for multi-drug treatment regimens as synergistic interactions have been observed when used in combination with conventional antibiotics. Due to this synergism and different mechanisms of action between AMPs and antibiotics, the probability of inducing pathogen resistance to antibiotics can be drastically reduced. AMPs that are currently in clinical trials for the treatment of other conditions should be investigated as potential candidates for the treatment of NTDs. These AMPs might prove to be effective against NTDs; for example, pexiganan, which is undergoing phase 3 clinical trials for diabetic foot ulcers, served as template for the development of an arginine-rich variant that displays potent anti-leishmanial activity. 
Table 2. Summary of selected AMPs that are associated with or display activity against neglected tropical diseases.

\begin{tabular}{|c|c|c|c|c|c|}
\hline Type & $\begin{array}{c}\text { Infection } \\
\text { (Causative Agent) }\end{array}$ & AMP & Source & Notes & Ref \\
\hline \multirow{6}{*}{ Bacterial } & \multirow{3}{*}{$\begin{array}{l}\text { Leprosy } \\
(\text { Mycobacterium leprae })\end{array}$} & Human $\beta$-defensin 3 & Homo sapiens (Human) & Up-regulated during a leprosy type 1 infections & [106] \\
\hline & & LL-37 & $\begin{array}{c}\text { Homo sapiens (Human) } \\
\text { Pan troglodytes (Chimpanzee) }\end{array}$ & M. leprae inhibits $C A M P$ - the gene encoding for LL-37 & [116] \\
\hline & & Hepcidin & Homo sapiens (Human) & Involved in the degradation of ferroportin in multibacillary lesions & [118] \\
\hline & \multirow{3}{*}{$\begin{array}{l}\text { Trachoma } \\
\text { (Chlamydia trachomatis) }\end{array}$} & SMAP-29 & Ovis aries (Sheep) & $\begin{array}{l}\text { Reduced inclusion number at concentration of } 10 \mu \mathrm{g} / \mathrm{mL} \text {. Compromised integrity of extracellular } \\
\text { elementary body }\end{array}$ & {$[130]$} \\
\hline & & Melittin & Apis mellifera (Honey bee) & $\begin{array}{l}\text { Direct cytotoxic effect on C. trachomatis. Hindering normal process of intracellular development by } \\
\text { lowering the transdermal potential and disrupting the adhesion of the bacteria to the cell }\end{array}$ & [133] \\
\hline & & Cyto-insectotoxin 1a & $\begin{array}{c}\text { Lachesana tarabaevi } \\
\text { (Central Asian ant spider) }\end{array}$ & $\begin{array}{l}\text { Inhibit } C \text {. trachomatis infection at an early stage, with higher efficacy than melittin and negligible } \\
\text { effect on cell viability }\end{array}$ & [134] \\
\hline \multirow[t]{2}{*}{ Parasites } & \multirow{2}{*}{$\begin{array}{l}\text { Chagas disease } \\
\text { (Trypanosoma cruzi) }\end{array}$} & Melittin & A. mellifera (Honey bee) & $\begin{array}{l}\text { Induced morphological alterations in the different developmental forms of the parasite, which could be } \\
\text { characterized as apoptosis and autophagy. }\end{array}$ & [145] \\
\hline & & Dermasiptin-01 & Phyllomedusa oreades (Tree frog) & Lytic activity & [149] \\
\hline \multirow{8}{*}{ Parasites } & $\begin{array}{l}\text { Chagas disease } \\
\text { (Trypanosoma cruzi) }\end{array}$ & Tachyplesin I & Tachypleus tridentatus (Horseshoe crab) & Able to kill $T$. cruzi epimastigote and promastigotes at micromolar concentrations. & [151] \\
\hline & Human African & Temporin-SHd & Pelophylax saharica (Sahara frog) & Growth inhibitory activity against $T$. brucei and $T$. cruzi & [155] \\
\hline & $\begin{array}{c}\text { Trypanosomiasis } \\
\text { (Trypanosoma brucei) }\end{array}$ & BMAP-27 & Bos Taurus (Cattle) & Inhibited both life cycles of both $T$. brucei at low micromolar concentrations & [157] \\
\hline & \multirow{5}{*}{$\begin{array}{l}\text { Leishmaniasis } \\
\text { (L. donovani, L. major, } \\
\text { L. tropica, L. Mexicana } \\
\text { and L. panamensis) }\end{array}$} & Temporin A and B & $\begin{array}{l}\text { Rana temporaria } \\
\text { (European common frog) }\end{array}$ & $\begin{array}{l}\text { Active against insect and mammalian stages at } 15-25 \mu \mathrm{M} \text { concentrations. Rapid disruption of plasma } \\
\text { membrane potential and decrease in intracellular ATP levels }\end{array}$ & {$[160]$} \\
\hline & & Dermaseptin S4 & $\begin{array}{l}\text { Phyllomedusa sauvagii, } \\
\text { (South America Sauvages leaf frog) }\end{array}$ & Potent lysis for $L$. major promastigotes. & [51] \\
\hline & & Dermasiptin-01 & Phyllomedusa oreades (tree frog) & Active against $L$. infantum promastigotes by membrane damage and flagella alterations & [164] \\
\hline & & Gomesin & $\begin{array}{l}\text { Acanthoscurria gomesiana } \\
\text { (Tarantula spider) }\end{array}$ & Decreased the viability of $L$. amazonensis promastigotes with little activity against human erythrocytes & [166] \\
\hline & & Indolicidin & Bovine leukocytes & Membrane effects and able to induce autophagy in $L$. donovani & [167] \\
\hline
\end{tabular}


Table 2. Cont.

\begin{tabular}{|c|c|c|c|c|c|}
\hline Type & $\begin{array}{c}\text { Infection } \\
\text { (Causative Agent) }\end{array}$ & AMP & Source & Notes & Ref \\
\hline Parasites & $\begin{array}{c}\text { Leishmaniasis } \\
\text { (L. donovani, L. major, } \\
\text { L. tropica, L. Mexicana } \\
\text { and L. panamensis) }\end{array}$ & Thionins & Triticum aestivum (Wheat) & $\begin{array}{l}\text { Proved effective against } L \text {. donovani promastigotes in the low micromolar range, } \\
\text { membrane permeability }\end{array}$ & {$[168]$} \\
\hline \multirow{3}{*}{ Helminths } & \multirow{3}{*}{$\begin{array}{c}\text { Onchocerciasis } \\
\text { (River blindness) } \\
\text { (Onchocerca volvulus) }\end{array}$} & HNP1-3 & Homo sapiens (Human) & $\begin{array}{l}\text { HNP1-3 can bind to Onchocerca volvulus surfaces and is known to mediate the macrophage } \\
\text { response against other micro-organisms by the release of IFN- } \gamma \text { and TNF- } \alpha\end{array}$ & {$[200]$} \\
\hline & & $\begin{array}{l}\text { Galectin } \\
\text { Peroxidoxin-2 }\end{array}$ & Onchocerca ochengi (Black fly) & $\begin{array}{l}\text { Excretory/secretory products of Onchocerca volvulus with significant antibacterial activity } \\
\text { against } E \text {. coli }\end{array}$ & \multirow[b]{2}{*}{ [11] } \\
\hline & & $\begin{array}{c}\text { ALT-1 } \\
\text { (all peptides are AMP } \\
\text { precursors) }\end{array}$ & Onchocerca volvulus (Roundworm) & The peptides Galectin, Peroxidoxin-2 and ALT-1 are all AMP precursors & \\
\hline \multirow{2}{*}{ Viruses } & $\begin{array}{l}\text { Dengue viral disease } \\
\text { (family Flaviviridae) }\end{array}$ & Latarcin & Lachesana tarabaevi (Ant spider) & Able to inhibit the replication of dengue viruses in in vitro cultured cells & {$[232,233]$} \\
\hline & Rabies (Lyssavirus) & $\mathrm{C} 2, \mathrm{C} 6, \mathrm{C} 8$ and $\mathrm{P} 16$ & Synthetic & $\begin{array}{l}\text { Synthetic AMPs based on naturally according peptides } \mathrm{C} 2, \mathrm{C} 6, \mathrm{C} 8 \text { and } \mathrm{P} 16 \text { peptides exhibited } \\
\text { strong rabies virus inhibitory properties }\end{array}$ & {$[252]$} \\
\hline
\end{tabular}


Currently, the greatest obstacle for the use of AMPs, which especially affects its use in the treatment of NTDs, is the cost of the large-scale synthesis of these peptides. Additionally, for large-scale application, isolation from natural sources is also not a viable option. Progress has been made in developing DNA recombinant methods to successfully synthesise and purify AMPs for therapeutic application in a cost effective manner [258-260], but the commercial feasibility of these methods still need to be evaluated. Also, because ribosomally synthesised AMPs are expressed by single genes, they may be considered for use in gene therapy for introduction directly into infected tissue. This could significantly reduce the cost associated with the large-scale production and purification of AMPs.

In conclusion, AMPs are effective against a variety of infectious diseases including NTDs. AMPs offer innovative treatment possibilities as they can be used as single anti-microbial agents and in combination with conventional antibiotics, as well as immunomodulating agents. Future research should focus on addressing the issues related to toxicity and challenges associated with mass manufacturing.

\section{Acknowledgments}

The authors would like to extend their gratitude to Annemarie Wentzel for assisting with language editing of the manuscript. Part of this work was funded by the National Research Foundation (NRF) of South Africa.

\section{Author Contributions}

All the authors were responsible for critical review of the manuscript. All of the authors were responsible for the writing of certain sections of the manuscript according to their field of expertise.

\section{Conflicts of Interest}

Any opinion, findings and conclusions or recommendations expressed in this material are those of the author(s) and therefore the NRF does not accept any liability in regard thereto.

The authors report no conflict of interest.

\section{References}

1. WHO. Neglected Tropical Diseases. Available online: http://www.who.int/neglected_diseases/ diseases/en/ (accessed on 18 August 2015).

2. Hotez, P.J.; Molyneuz, D.H.; Fenwick, A.; Ottesen, E.; Ehrlich Sachs, S.; Sachs, J.D. Incorporating a rapid-impact package for Neglected tropical diseases with programs for HIV/AIDS, tuberculosis, maleria. PLoS Med. 2006, 3, doi:10.1371/journal.pmed.0030102.

3. Feasey, N.; Wansbrough-Jones, M.; Mabey, D.C.; Solomon, A.W. Neglected tropical diseases. Br. Med. Bull. 2010, 93, 179-200.

4. Fox, J.L. Antimicrobial peptides stage a comeback. Nat. Biotechnol. 2013, 31, 379-382.

5. Hancock, R.E.; Lehrer, R. Cationic peptides: A new source of antibiotics. Trends Biotechnol. 1998, 16, 82-88.

6. Wagner, D.; Young, L.S. Nontuberculous mycobacterial infections: A clinical review. Infection 2004, 32, 257-270. 
7. Gordon, Y.J.; Romanowski, E.G.; McDermott, A.M. A review of antimicrobial peptides and their therapeutic potential as anti-infective drugs. Curr. Res. 2005, 30, 505-515.

8. Hancock, R.E.; Sahl, H.G. Antimicrobial and host-defense peptides as new anti-infective therapeutic strategies. Nat. Biotechnol. 2006, 24, 1551-1557.

9. Jones, E.; Salin, V.; Williams, G.W. Nisin and the Market for Commercial Bacteriocins. TAMRC Consumer and Product Research Report No. CP-01-05. 2005. Avaliable online: http://wwww. ageconsearch.umn.edu/bitstream/90779/2/CP\%2001\%2005\%20Nisin\%20Report.pdf (accessed on 18 August 2015).

10. Jenssen, H.; Hamill, P.; Hancock, R.E. Peptide antimicrobial agents. Clin. Microbiol. Rev. 2006, 19, 491-511.

11. Eberle, R.; Brattig, N.W.; Trusch, M.; Schlüter, H.; Achukwi, M.D.; Eisenbarth, A.; Renz, A.; Liebau, E.; Perbandt, M.; Betzel, C. Isolation, identification and functional profile of excretory-secretory peptides from Onchocerca ochengi. Acta Tropica 2015, 142, 156-166.

12. Wang, G.; Li, X.; Wang, Z. The Antimicrobial Peptide Database. Available online: http://wwww. aps.unmc.edu/AP/main.php (accesed on 22 June 2015).

13. Wang, G.; Li, X.; Wang, Z. APD2: The updated antimicrobial peptide database and its application in peptide design. Nucleic Acids Res. 2009, 37, D933-D937.

14. Wang, Z.; Wang, G. APD: The Antimicrobial Peptide Database. Nucleic Acids Res. 2004, 32, D590-D592.

15. Papagianni, M. Ribosomally synthesized peptides with antimicrobial properties: Biosynthesis, structure, function, and applications. Biotechnol. Adv. 2003, 21, 465-499.

16. Felnagle, E.A.; Jackson, E.E.; Chan, Y.A.; Podevels, A.M.; Berti, A.D.; McMahon, M.D.; Thomas, M.G. Nonribosomal peptide synthetases involved in the production of medically relevant natural products. Mol. Pharm. 2008, 5, 191-211.

17. Niggemann, J.; Bozko, P.; Bruns, N.; Wodtke, A.; Gieseler, M.T.; Thomas, K.; Jahns, C.; Nimtz, M.; Reupke, I.; Bruser, T.; et al. Baceridin, a cyclic hexapeptide from an epiphytic Bacillus strain, inhibits the proteasome. Chem. Biol. Chem. 2014, 15, 1021-1029.

18. Wang, G.; Mishra, B.; Lau, K.; Lushnikova, T.; Golla, R.; Wang, X. Antimicrobial peptides in 2014. Pharmaceuticals 2015, 8, 123-150.

19. Midorikawa, K.; Ouhara, K.; Komatsuzawa, H.; Kawai, T.; Yamada, S.; Fujiwara, T.; Yamazaki, K.; Sayama, K.; Taubman, M.A.; Kurihara, H.; et al. Staphylococcus aureus susceptibility to innate antimicrobial peptides, beta-defensins and CAP18, expressed by human keratinocytes. Infect. Immun. 2003, 71, 3730-3739.

20. Hancock, R.E.; Diamond, G. The role of cationic antimicrobial peptides in innate host defences. Trends Microbiol. 2000, 8, 402-410.

21. Akira, S.; Uematsu, S.; Takeuchi, O. Pathogen recognition and innate immunity. Cell 2006, 124, 783-801.

22. Jensen, S.; Thomsen, A.R. Sensing of RNA viruses: A review of innate immune receptors involved in recognizing RNA virus invasion. J. Virol. 2012, 86, 2900-2910.

23. Loo, Y.M.; Fornek, J.; Crochet, N.; Bajwa, G.; Perwitasari, O.; Martinez-Sobrido, L.; Akira, S.; Gill, M.A.; Garcia-Sastre, A.; Katze, M.G.; et al. Distinct RIG-I and MDA5 signaling by RNA viruses in innate immunity. J. Virol. 2008, 82, 335-345. 
24. Cotter, P.D.; Hill, C.; Ross, R.P. Bacteriocins: Developing innate immunity for food. Nat. Rev. Microbiol. 2005, 3, 777-788.

25. Brogden, K.A. Antimicrobial peptides: Pore formers or metabolic inhibitors in bacteria? Nat. Rev. Microbiol. 2005, 3, 238-250.

26. Matsuzaki, K. Control of cell selectivity of antimicrobial peptides. Biochim. Biophys. Acta 2009, 1788, 1687-1692.

27. Takahashi, D.; Shukla, S.K.; Prakash, O.; Zhang, G. Structural determinants of host defense peptides for antimicrobial activity and target cell selectivity. Biochimie 2010, 92, 1236-1241.

28. Harris, F.; Dennison, S.R.; Phoenix, D.A. Anionic antimicrobial peptides from eukaryotic organisms. Curr. Protein Pept. Sci. 2009, 10, 585-606.

29. Laverty, G.; Gorman, S.P.; Gilmore, B.F. The potential of antimicrobial peptides as biocides. Int. J. Mol. Sci. 2011, 12, 6566-6596.

30. Brogden, K.A.; Ackermann, M.; McCray, P.B., Jr.; Tack, B.F. Antimicrobial peptides in animals and their role in host defences. Int. J. Antimicrob. Agents 2003, 22, 465-478.

31. Huang, Y.; Huang, J.; Chen, Y. Alpha-helical cationic antimicrobial peptides: Relationships of structure and function. Protein Cell 2010, 1, 143-152.

32. Boman, H.G. Gene-encoded peptide antibiotics and the concept of innate immunity: An update review. Scand. J. Immunol. 1998, 48, 15-25.

33. Buchan, D.W.A.; Minneci, F.; Nugent, T.C.O.; Bryson, K.; Jones, D.T. Scalable web services for the PSIPRED Protein Analysis Workbench. Nucleic Acids Res. 2013, 41, 340-348.

34. Vale, N.; Aguiar, L.; Gomes, P. Antimicrobial peptides: A new class of antimalarial drugs? Front. Pharmacol. 2014, 5, doi:10.3389/fphar.2014.00275.

35. Fujikawa, K.; Suketa, Y.; Hayashi, K.; Suzuki, T. Chemical structure of circulin A. Experientia 1965, 21, 307-308.

36. Craik, D.J.; Daly, N.L.; Bond, T.; Waine, C. Plant cyclotides: A unique family of cyclic and knotted proteins that defines the cyclic cystine knot structural motif. J. Mol. Biol. 1999, 294, 1327-1336.

37. Lehrer, R.I.; Cole, A.M.; Selsted, M.E. Theta-Defensins: Cyclic peptides with endless potential. J. Biol. Chem. 2012, 287, 27014-27019.

38. Van Dijk, A.; Molhoek, E.M.; Bikker, F.J.; Yu, P.L.; Veldhuizen, E.J.; Haagsman, H.P. Avian cathelicidins: Paradigms for the development of anti-infectives. Vet. Microbiol. 2011, 153, 27-36.

39. Ma, D.; Zhou, C.; Zhang, M.; Han, Z.; Shao, Y.; Liu, S. Functional analysis and induction of four novel goose (Anser cygnoides) avian beta-defensins in response to salmonella enteritidis infection. Comp. Immunol. Microbiol. Infecti. Dis. 2012, 35, 197-207.

40. Scocchi, M.; Pallavicini, A.; Salgaro, R.; Bociek, K.; Gennaro, R. The salmonid cathelicidins: A gene family with highly varied C-terminal antimicrobial domains. Comp. Biochem. Physiol. B Biochem. Mol. Biol. 2009, 152, 376-381.

41. Casadei, E.; Wang, T.; Zou, J.; Gonzalez Vecino, J.L.; Wadsworth, S.; Secombes, C.J. Characterization of three novel beta-defensin antimicrobial peptides in rainbow trout (Oncorhynchus mykiss). Mol. Immunol. 2009, 46, 3358-3366.

42. Alibardi, L. Immunocytochemical detection of beta-defensins and cathelicidins in the secretory granules of the tongue in the lizard Anolis carolinensis. Acta Histochem. 2015, 117, 223-227. 
43. Zhao, H.; Gan, T.X.; Liu, X.D.; Jin, Y.; Lee, W.H.; Shen, J.H.; Zhang, Y. Identification and characterization of novel reptile cathelicidins from elapid snakes. Peptides 2008, 29, 1685-1691.

44. Lin, K.F.; Lee, T.R.; Tsai, P.H.; Hsu, M.P.; Chen, C.S.; Lyu, P.C. Structure-based protein engineering for alpha-amylase inhibitory activity of plant defensin. Proteins 2007, 68, 530-540.

45. Cornet, B.; Bonmatin, J.M.; Hetru, C.; Hoffmann, J.A.; Ptak, M.; Vovelle, F. Refined three-dimensional solution structure of insect defensin A. Structure 1995, 3, 435-448.

46. Ramanathan, B.; Davis, E.G.; Ross, C.R.; Blecha, F. Cathelicidins: Microbicidal activity, mechanisms of action, and roles in innate immunity. Microbes Infect. 2002, 4, 361-372.

47. Ganz, T. Defensins: Antimicrobial peptides of innate immunity. Nat. Rev. Immunol. 2003, 3, 710-720.

48. Suarez-Carmona, M.; Hubert, P.; Delvenne, P.; Herfs, M. Defensins: "Simple" antimicrobial peptides or broad-spectrum molecules? Cytokine Growth Factor Rev. 2015, 26, 361-370.

49. Vandamme, D.; Landuyt, B.; Luyten, W.; Schoofs, L. A comprehensive summary of LL-37, the factotum human cathelicidin peptide. Cellular Immunol. 2012, 280, 22-35.

50. Zanetti, M.; Gennaro, R.; Romeo, D. Cathelicidins: A novel protein family with a common proregion and a variable C-terminal antimicrobial domain. FEBS Lett. 1995, 374, 1-5.

51. Feder, R.; Dagan, A.; Mor, A. Structure-activity relationship study of antimicrobial dermaseptin S4 showing the consequences of peptide oligomerization on selective cytotoxicity. J. Biol. Chem. 2000, 275, 4230-4238.

52. Unger, T.; Oren, Z.; Shai, Y. The effect of cyclization of magainin 2 and melittin analogues on structure, function, and model membrane interactions: Implication to their mode of action. Biochemistry 2001, 40, 6388-6397.

53. Yeaman, M.R.; Yount, N.Y. Mechanisms of antimicrobial peptide action and resistance. Pharmacol. Rev. 2003, 55, 27-55.

54. Torrent, M.; Pulido, D.; Rivas, L.; Andreu, D. Antimicrobial peptide action on parasites. Curr. Drug Targets 2012, 13, 1138-1147.

55. Park, C.; Lee, D.G. Fungicidal effect of antimicrobial peptide arenicin-1. Biochim. Biophys. Acta 2009, 1788, 1790-1796.

56. Dean, R.E.; O’Brien, L.M.; Thwaite, J.E.; Fox, M.A.; Atkins, H.; Ulaeto, D.O. A carpet-based mechanism for direct antimicrobial peptide activity against vaccinia virus membranes. Peptides 2010, 31, 1966-1972.

57. Klotman, M.E.; Chang, T.L. Defensins in innate antiviral immunity. Nat. Rev. Immunol. 2006, 6, $447-456$.

58. Xiong, Y.Q.; Mukhopadhyay, K.; Yeaman, M.R.; Adler-Moore, J.; Bayer, A.S. Functional interrelationships between cell membrane and cell wall in antimicrobial peptide-mediated killing of Staphylococcus aureus. Antimicrob. Agents Chemother. 2005, 49, 3114-3121.

59. Gee, M.L.; Burton, M.; Grevis-James, A.; Hossain, M.A.; McArthur, S.; Palombo, E.A.; Wade, J.D.; Clayton, A.H. Imaging the action of antimicrobial peptides on living bacterial cells. Sci. Rep. 2013, 3, 1557-1563.

60. Powers, J.P.; Hancock, R.E. The relationship between peptide structure and antibacterial activity. Peptides 2003, 24, 1681-1691. 
61. Baumann, G.; Mueller, P. A molecular model of membrane excitability. J. Supramol. Struct. 1974, 2, 538-557.

62. Yang, L.; Harroun, T.A.; Weiss, T.M.; Ding, L.; Huang, H.W. Barrel-stave model or toroidal model? A case study on melittin pores. Biophys. J. 2001, 81, 1475-1485.

63. Carnicelli, V.; Lizzi, A.R.; Ponzi, A.; Amicosante, G.; Bozzi, A.; di Giulio, A. Interaction between antimicrobial peptides (AMPs) and their primary target, the biomembranes. In Microbial Pathogens and Strategies for Combating Them: Science, Technology and Education; Méndez-Vilas, A., Ed.; Formatex Research Center: Badajoz, Spain, 2013; Volume 2, pp. 1123-1134.

64. Matsuzaki, K.; Sugishita, K.; Harada, M.; Fujii, N.; Miyajima, K. Interactions of an antimicrobial peptide, magainin 2, with outer and inner membranes of Gram-negative bacteria. Biochim. Biophys. Acta 1997, 1327, 119-130.

65. Pandey, B.K.; Srivastava, S.; Singh, M.; Ghosh, J.K. Inducing toxicity by introducing a leucine-zipper-like motif in frog antimicrobial peptide, magainin 2. Biochem. J. 2011, 436, 609-620.

66. Koo, S.P.; Bayer, A.S.; Yeaman, M.R. Diversity in antistaphylococcal mechanisms among membrane-targeting antimicrobial peptides. Infect. Immun. 2001, 69, 4916-4922.

67. Podda, E.; Benincasa, M.; Pacor, S.; Micali, F.; Mattiuzzo, M.; Gennaro, R.; Scocchi, M. Dual mode of action of Bac7, a proline-rich antibacterial peptide. Biochim. Biophys. Acta 2006, 1760, 1732-1740.

68. Nicolas, P. Multifunctional host defense peptides: Intracellular-targeting antimicrobial peptides. FEBS J. 2009, 276, 6483-6496.

69. Otvos, L., Jr. Antibacterial peptides and proteins with multiple cellular targets. J. Pept. Sci. An Off. Publ. Europ. Pept. Soc. 2005, 11, 697-706.

70. Bowdish, D.M.; Davidson, D.J.; Hancock, R.E. A re-evaluation of the role of host defence peptides in mammalian immunity. Curr. Protein Pept. Sci. 2005, 6, 35-51.

71. Wu, G.; Ding, J.; Li, H.; Li, L.; Zhao, R.; Shen, Z.; Fan, X.; Xi, T. Effects of cations and pH on antimicrobial activity of thanatin and $s$-thanatin against Escherichia coli ATCC25922 and B. subtilis ATCC 21332. Curr. Microbiol. 2008, 57, 552-557.

72. Johansson, J.; Gudmundsson, G.H.; Rottenberg, M.E.; Berndt, K.D.; Agerberth, B. Conformation-dependent antibacterial activity of the naturally occurring human peptide LL-37. J. Biol. Chem. 1998, 273, 3718-2374.

73. Niyonsaba, F.; Hirata, M.; Ogawa, H.; Nagaoka, I. Epithelial cell-derived antibacterial peptides human beta-defensins and cathelicidin: Multifunctional activities on mast cells. Curr. Drug Targets Inflamm. Allergy 2003, 2, 224-231.

74. Oppenheim, J.J.; Biragyn, A.; Kwak, L.W.; Yang, D. Roles of antimicrobial peptides such as defensins in innate and adaptive immunity. Annals Rheum. Dis. 2003, 62, ii17-ii21.

75. Scott, M.G.; Davidson, D.J.; Gold, M.R.; Bowdish, D.; Hancock, R.E. The human antimicrobial peptide LL-37 is a multifunctional modulator of innate immune responses. J. Immunol. 2002, 169, 3883-3891.

76. Tjabringa, G.S.; Aarbiou, J.; Ninaber, D.K.; Drijfhout, J.W.; Sorensen, O.E.; Borregaard, N.; Rabe, K.F.; Hiemstra, P.S. The antimicrobial peptide LL-37 activates innate immunity at the airway epithelial surface by transactivation of the epidermal growth factor receptor. J. Immunol. 2003, $171,6690-6696$. 
77. Yang, D.; Biragyn, A.; Hoover, D.M.; Lubkowski, J.; Oppenheim, J.J. Multiple roles of antimicrobial defensins, cathelicidins, and eosinophil-derived neurotoxin in host defense. Annu. Rev. Immunol. 2004, 22, 181-215.

78. Gough, M.; Hancock, R.E.; Kelly, N.M. Antiendotoxin activity of cationic peptide antimicrobial agents. Infect. Immun. 1996, 64, 4922-4927.

79. Bucki, R.; Pastore, J.J.; Randhawa, P.; Vegners, R.; Weiner, D.J.; Janmey, P.A. Antibacterial activities of rhodamine B-conjugated gelsolin-derived peptides compared to those of the antimicrobial peptides cathelicidin LL37, magainin II, and melittin. Antimicrob. Agents Chemother. 2004, 48, 1526-1533.

80. Marr, A.K.; Gooderham, W.J.; Hancock, R.E. Antibacterial peptides for therapeutic use: Obstacles and realistic outlook. Curr. Opin. Pharmacol. 2006, 6, 468-472.

81. Sun, X.; Chen, S.; Li, S.; Yan, H.; Fan, Y.; Mi, H. Deletion of two C-terminal Gln residues of 12-26-residue fragment of melittin improves its antimicrobial activity. Peptides 2005, 26, 369-375.

82. Blondelle, S.E.; Houghten, R.A. Hemolytic and antimicrobial activities of the twenty-four individual omission analogues of melittin. Biochemistry 1991, 30, 4671-4678.

83. Asthana, N.; Yadav, S.P.; Ghosh, J.K. Dissection of antibacterial and toxic activity of melittin: A leucine zipper motif plays a crucial role in determining its hemolytic activity but not antibacterial activity. J. Biol. Chem. 2004, 279, 55042-55050.

84. Wu, R.; Wang, Q.; Zheng, Z.; Zhao, L.; Shang, Y.; Wei, X.; Liao, X.; Zhang, R. Design, characterization and expression of a novel hybrid peptides melittin (1-13)-LL37 (17-30). Mol. Biol. Rep. 2014, 41, 4163-4169.

85. Brogden, N.K.; Brogden, K.A. Will new generations of modified antimicrobial peptides improve their potential as pharmaceuticals? Int. J. Antimicrob. Agents 2011, 38, 217-225.

86. Finlay, B.B.; Hancock, R.E. Can innate immunity be enhanced to treat microbial infections? Nat. Rev. Microbiol. 2004, 2, 497-504.

87. Marais, E.; Hamman, J.; Plessis, L.; Lemmer, R.; Steenekamp, J. Eudragit(R) L100/N-trimethylchitosan chloride microspheres for oral insulin delivery. Molecules 2013, 18, 6734-6747.

88. Sarmento, B.; Ribeiro, A.; Veiga, F.; Ferreira, D.; Neufeld, R. Oral bioavailability of insulin contained in polysaccharide nanoparticles. Biomacromolecules 2007, 8, 3054-3060.

89. Huang, C.; Jin, H.; Qian, Y.; Qi, S.; Luo, H.; Luo, Q.; Zhang, Z. Hybrid melittin cytolytic Peptide-driven ultrasmall lipid nanoparticles block melanoma growth in vivo. ACS Nano 2013, 7 , 5791-5800.

90. Piras, A.M.; Maisetta, G.; Sandreschi, S.; Gazzarri, M.; Bartoli, C.; Grassi, L.; Esin, S.; Chiellini, F.; Batoni, G. Chitosan nanoparticles loaded with the antimicrobial peptide temporin B exert a long-term antibacterial activity in vitro against clinical isolates of Staphylococcus epidermidis. Front. Microbiol. 2015, 6, doi:10.3389/fmicb.2015.00372.

91. Mataraci, E.; Dosler, S. In vitro activities of antibiotics and antimicrobial cationic peptides alone and in combination against methicillin-resistant Staphylococcus aureus biofilms. Antimicrob. Agents Chemother. 2012, 56, 6366-6371.

92. Engels, D.; Savioli, L. Reconsidering the underestimated burden caused by Neglected tropical diseases. Trends Parasitol. 2006, 22, 363-366. 
93. Gallagher, M.; Malhotra, I.; Mungai, P.L.; Wamachi, A.N.; Kioko, J.M.; Ouma, J.H.; Muchiri, E.; King, C.L. The effects of maternal helminth and malaria infections on mother-to-child HIV transmission. Aids 2005, 19, 1849-1855.

94. Hotez, P.J.; Molyneux, D.H.; Fenwick, A.; Kumaresan, J.; Sachs, S.E.; Sachs, J.D.; Savioli, L. Control of Neglected tropical diseases. N. Engl. J. Med. 2007, 357, 1018-1027.

95. Hotez, P.J.; Fenwick, A.; Savioli, L.; Molyneux, D.H. Rescuing the bottom billion through control of Neglected tropical diseases. Lancet 2009, 373, 1570-1575.

96. Norris, J.; Adelman, C.; Spantchak, Y.; Marano, K. Social and Economic Impact Review on Neglected Tropical Diseases; Hudson Institute's Center for Science in Public Policy: Washington, DC, USA, 2012; pp. 1-26.

97. WHO. Antimicrobial Resistance: Fact sheet $\mathrm{N}^{\circ}$ 194. Available online: http://www.who.int/ mediacentre/factsheets/fs194/en/ (accessed on 18 August 2015).

98. Zucca, M.; Savoia, D. The post-antibiotic era: Promising developments in the therapy of infectious diseases. Int. J. Biomed. Sci.: IJBS 2010, 6, 77-86.

99. Barrow, W.W. Processing of mycobacterial lipids and effects on host responsiveness. Front. Biosci. A J. Virtual Lib. 1997, 2, d387-d400.

100. Barrow, W.W. Treatment of mycobacterial infections. Rev. Scientifique Tech. 2001, 20, 55-70.

101. Mendez-Samperio, P. The human cathelicidin hCAP18/LL-37: A multifunctional peptide involved in mycobacterial infections. Peptides 2010, 31, 1791-1798.

102. Turner, J.; Cho, Y.; Dinh, N.N.; Waring, A.J.; Lehrer, R.I. Activities of LL-37, a cathelin-associated antimicrobial peptide of human neutrophils. Antimicrob. Agents Chemother. 1998, 42, 2206-2214.

103. Gilliet, M.; Lande, R. Antimicrobial peptides and self-DNA in autoimmune skin inflammation. Curr. Opin. Immunol. 2008, 20, 401-407.

104. Monot, M.; Honore, N.; Garnier, T.; Araoz, R.; Coppee, J.Y.; Lacroix, C.; Sow, S.; Spencer, J.S.; Truman, R.W.; Williams, D.L.; et al. On the origin of leprosy. Science 2005, 308, 1040-1042.

105. WHO Leprosy Fact Sheet $\mathrm{N}^{\circ}$ 101. Available online:http://www.who.int/mediacentre/factsheets/ fs101/en/(accessed on 18 August 2015).

106. Cogen, A.L.; Walker, S.L.; Roberts, C.H.; Hagge, D.A.; Neupane, K.D.; Khadge, S.; Lockwood, D.N. Human beta-defensin 3 is up-regulated in cutaneous leprosy type 1 reactions. PLoS Negl. Trop. Dis. 2012, 6, e1869.

107. Bennett, B.H.; Parker, D.L.; Robson, M. Leprosy: Steps along the journey of eradication. Public Health Rep. 2008, 123, 198-205.

108. Cole, S.T.; Eiglmeier, K.; Parkhill, J.; James, K.D.; Thomson, N.R.; Wheeler, P.R.; Honore, N.; Garnier, T.; Churcher, C.; Harris, D.; et al. Massive gene decay in the leprosy bacillus. Nature 2001, 409, 1007-1011.

109. Cole, S.T.; Brosch, R.; Parkhill, J.; Garnier, T.; Churcher, C.; Harris, D.; Gordon, S.V.; Eiglmeier, K.; Gas, S.; Barry, C.E., 3rd; et al. Deciphering the biology of Mycobacterium tuberculosis from the complete genome sequence. Nature 1998, 393, 537-544.

110. Irgens, L.M. The discovery of the leprosy bacillus. Tidsskr. Norske Laegeforening Tidsskr. Prakt. Med. Ny Raekke 2002, 122, 708-709. 
111. De Messias-Reason, I.; Kremsner, P.G.; Kun, J.F. Functional haplotypes that produce normal ficolin-2 levels protect against clinical leprosy. J. Infect. Dis. 2009, 199, 801-804.

112. Rees, R.J.; Pearson, J.M.; Waters, M.F. Experimental and clinical studies on rifampicin in treatment of leprosy. Br. Med. J. 1970, 1, 89-92.

113. Pinheiro, R.O.; de Souza Salles, J.; Sarno, E.N.; Sampaio, E.P. Mycobacterium leprae-host-cell interactions and genetic determinants in leprosy: An overview. Future Microbiol. 2011, 6, 217-230.

114. Bochud, P.Y.; Hawn, T.R.; Siddiqui, M.R.; Saunderson, P.; Britton, S.; Abraham, I.; Argaw, A.T.; Janer, M.; Zhao, L.P.; Kaplan, G.; et al. Toll-like receptor 2 (TLR2) polymorphisms are associated with reversal reaction in leprosy. J. Infect. Dis. 2008, 197, 253-261.

115. Liu, P.T.; Stenger, S.; Li, H.; Wenzel, L.; Tan, B.H.; Krutzik, S.R.; Ochoa, M.T.; Schauber, J.; $\mathrm{Wu}, \mathrm{K}$; Meinken, C.; et al. Toll-like receptor triggering of a vitamin D-mediated human antimicrobial response. Science 2006, 311, 1770-1773.

116. Liu, P.T.; Wheelwright, M.; Teles, R.; Komisopoulou, E.; Edfeldt, K.; Ferguson, B.; Mehta, M.D.; Vazirnia, A.; Rea, T.H.; Sarno, E.N.; et al. MicroRNA-21 targets the vitamin D-dependent antimicrobial pathway in leprosy. Nat. Med. 2012, 18, 267-273.

117. Nemeth, E.; Rivera, S.; Gabayan, V.; Keller, C.; Taudorf, S.; Pedersen, B.K.; Ganz, T. IL-6 mediates hypoferremia of inflammation by inducing the synthesis of the iron regulatory hormone hepcidin. J. Clin. Investig. 2004, 113, 1271-1276.

118. Johnson, E.E.; Wessling-Resnick, M. Iron metabolism and the innate immune response to infection. Microbes Infect. 2012, 14, 207-216.

119. Rodriguez-Rojas, A.; Rodriguez-Beltran, J.; Couce, A.; Blazquez, J. Antibiotics and antibiotic resistance: A bitter fight against evolution. Int. J. Med. Microbiol. 2013, 303, 293-297.

120. Bechtle, M.; Chen, S.; Efferth, T. Neglected diseases caused by bacterial infections. Curr. Med. Chem. 2010, 17, 42-60.

121. WHO. Trachoma: Fact Sheet $N^{\circ}$ 382. Available online: http://www.who.int/mediacentre/ factsheets/fs382/en/ (accessed on 18 August 2015).

122. Courtright, P.; West, S.K. Contribution of sex-linked biology and gender roles to disparities with trachoma. Emerg. Infect. Dis. 2004, 10, 2012-2016.

123. Solomon, A.W.; Peeling, R.W.; Foster, A.; Mabey, D.C. Diagnosis and assessment of trachoma. Clin. Microbiol.Rev. 2004, 17, 982-1011.

124. Mabey, D.C.; Solomon, A.W.; Foster, A. Trachoma. Lancet 2003, 362, 223-239.

125. Burton, M.J. Trachoma: An overview. Br. Med. Bull. 2007, 84, 99-116.

126. Potroz, M.G.; Cho, N.J. Natural products for the treatment of trachoma and Chlamydia trachomatis. Molecules 2015, 20, 4180-4203.

127. WHO. Report of the 2nd Global Scientific Meeting on Trachoma. Avaliable online: http://www.who.int/blindness/2nd\%20GLOBAL\%20SCIENTIFIC\%20MEETING.pdf (accessed on 18 August 2015).

128. Solomon, A.W.; Holland, M.J.; Alexander, N.D.; Massae, P.A.; Aguirre, A.; Natividad-Sancho, A.; Molina, S.; Safari, S.; Shao, J.F.; Courtright, P.; et al. Mass treatment with single-dose azithromycin for trachoma. N. Engl. J. Med. 2004, 351, 1962-1971. 
129. Evans, J.R.; Solomon, A.W. Antibiotics for Trachoma. Cochrane Database Syst. Rev. 2011, doi:10.1002/14651858.CD001860.pub3.

130. Donati, M.; di Leo, K.; Benincasa, M.; Cavrini, F.; Accardo, S.; Moroni, A.; Gennaro, R.; Cevenini, R. Activity of cathelicidin peptides against Chlamydia spp. Antimicrob. Agents Chemother. 2005, 49, 1201-1202.

131. Dawson, R.M.; Liu, C.Q. Cathelicidin peptide SMAP-29: Comprehensive review of its properties and potential as a novel class of antibiotics. Drug Dev. Res. 2009, 70, 481-498.

132. Huang, G.T.; Zhang, H.B.; Kim, D.; Liu, L.; Ganz, T. A model for antimicrobial gene therapy: Demonstration of human beta-defensin 2 antimicrobial activities in vivo. Hum. Gene Ther. 2002, 13, 2017-2025.

133. Lazarev, V.N.; Parfenova, T.M.; Gularyan, S.K.; Misyurina, O.Y.; Akopian, T.A.; Govorun, V.M. Induced expression of melittin, an antimicrobial peptide, inhibits infection by Chlamydia trachomatis and Mycoplasma hominis in a HeLa cell line. Int. J. Antimicrob. Agents 2002, 19, 133-137.

134. Lazarev, V.N.; Shkarupeta, M.M.; Polina, N.F.; Kostrjukova, E.S.; Vassilevski, A.A.; Kozlov, S.A.; Grishin, E.V.; Govorun, V.M. Antimicrobial peptide from spider venom inhibits Chlamydia trachomatis infection at an early stage. Arch. Microbiol. 2013, 195, 173-179.

135. Lazarev, V.N.; Shkarupeta, M.M.; Titova, G.A.; Kostrjukova, E.S.; Akopian, T.A.; Govorun, V.M. Effect of induced expression of an antimicrobial peptide melittin on Chlamydia trachomatis and Mycoplasma hominis infections in vivo. Biochem. Biophys. Res. Commun. 2005, 338, 946-950.

136. Cox, F.E.G. Parasitic protozoa. In Modern Parasitology: A Textbook of Parasitology, 2nd ed.; Cox, F.E.G., Ed.; Blackwell Science Ltd: Oxford, UK, 1996; p. 276.

137. Spicer, J.W. Clinical Bacteriology, Mycology and Parasitology; Harcourt Publishers Ltd: London, UK, 2000; p. 221.

138. Andrews, K.T.; Fisher, G.; Skinner-Adams, T.S. Drug repurposing and human parasitic protozoan diseases. Int. J. Parasitol. Drugs Drug Resist. 2014, 4, 95-111.

139. McGwire, B.S.; Kulkarni, M.M. Interactions of antimicrobial peptides with Leishmania and trypanosomes and their functional role in host parasitism. Exp. Parasitol. 2010, 126, 397-405.

140. WHO. Chagas Disease (American Trypanosomiasis). Fact Sheet No 340 March 2015. Avaliable online: http://www.who.int/chagas/en/ (accessed on 18 August 2015).

141. Bern, C.; Montgomery, S.P.; Herwaldt, B.L.; Rassi, A., Jr.; Marin-Neto, J.A.; Dantas, R.O.; Maguire, J.H.; Acquatella, H.; Morillo, C.; Kirchhoff, L.V.; et al. Evaluation and treatment of chagas disease in the United States: A systematic review. JAMA 2007, 298, 2171-2181.

142. Soy, D.; Aldasoro, E.; Guerrero, L.; Posada, E.; Serret, N.; Mejia, T.; Urbina, J.A.; Gascon, J. Population pharmacokinetics of benznidazole in adult patients with chagas disease. Antimicrob. Agents Chemother. 2015, 59, 3342-3349.

143. Urbina, J.A. Recent clinical trials for the etiological treatment of chronic chagas disease: Advances, challenges and perspectives. J. Eukaryot. Microbiol. 2015, 62, 149-156.

144. Adade, C.M.; Chagas, G.S.; Souto-Padron, T. Apis mellifera venom induces different cell death pathways in Trypanosoma cruzi. Parasitology 2012, 139, 1444-1461. 
145. Adade, C.M.; Oliveira, I.R.; Pais, J.A.; Souto-Padron, T. Melittin peptide kills Trypanosoma cruzi parasites by inducing different cell death pathways. Toxicon 2013, 69, 227-239.

146. Fieck, A.; Hurwitz, I.; Kang, A.S.; Durvasula, R. Trypanosoma cruzi: Synergistic cytotoxicity of multiple amphipathic anti-microbial peptides to $\mathrm{T}$. cruzi and potential bacterial hosts. Exp. Parasitol. 2010, 125, 342-347.

147. Huang, C.M.; Chen, H.C.; Zierdt, C.H. Magainin analogs effective against pathogenic protozoa. Antimicrob. Agents Chemother. 1990, 34, 1824-1826.

148. Jaynes, J.M.; Burton, C.A.; Barr, S.B.; Jeffers, G.W.; Julian, G.R.; White, K.L.; Enright, F.M.; Klei, T.R.; Laine, R.A. In vitro cytocidal effect of novel lytic peptides on Plasmodium falciparum and Trypanosoma cruzi. FASEB J. 1988, 2, 2878-2883.

149. Brand, G.D.; Leite, J.R.; Silva, L.P.; Albuquerque, S.; Prates, M.V.; Azevedo, R.B.; Carregaro, V.; Silva, J.S.; Sa, V.C.; Brandao, R.A.; et al. Dermaseptins from Phyllomedusa oreades and Phyllomedusa distincta. Anti-Trypanosoma cruzi activity without cytotoxicity to mammalian cells. J. Biol. Chem. 2002, 277, 49332-49340.

150. Pinto, E.G.; Pimenta, D.C.; Antoniazzi, M.M.; Jared, C.; Tempone, A.G. Antimicrobial peptides isolated from Phyllomedusa nordestina (Amphibia) alter the permeability of plasma membrane of Leishmania and Trypanosoma cruzi. Exp. Parasitol. 2013, 135, 655-660.

151. Lofgren, S.E.; Miletti, L.C.; Steindel, M.; Bachere, E.; Barracco, M.A. Trypanocidal and leishmanicidal activities of different antimicrobial peptides (AMPs) isolated from aquatic animals. Exp. Parasitol. 2008, 118, 197-202.

152. Barrett, M.P.; Boykin, D.W.; Brun, R.; Tidwell, R.R. Human African trypanosomiasis: Pharmacololgical re-engagement with a neglected disease. Br. J. Pharmacol. 2007, 152, 1155-1171.

153. WHO. Trypanosomiasis, Human African (Sleeping Sickness). Fact Sheet No. 259 May 2015. Avaliable online: http://www.who.int/mediacentre/factsheets/fs259/en/(accessed on 18 August 2015).

154. Brun, R.; Blum, J.; Chappuis, F.; Burri, C. Human African trypanosomiasis. Lancet 2010, 375, $148-159$.

155. Abbassi, F.; Raja, Z.; Oury, B.; Gazanion, E.; Piesse, C.; Sereno, D.; Nicolas, P.; Foulon, T.; Ladram, A. Antibacterial and leishmanicidal activities of temporin-SHd, a 17-residue long membrane-damaging peptide. Biochimie 2013, 95, 388-399.

156. McGwire, B.S.; Olson, C.L.; Tack, B.F.; Engman, D.M. Killing of African trypanosomes by antimicrobial peptides. J. Infect. Dis. 2003, 188, 146-152.

157. Haines, L.R.; Thomas, J.M.; Jackson, A.M.; Eyford, B.A.; Razavi, M.; Watson, C.N.; Gowen, B.; Hancock, R.E.; Pearson, T.W. Killing of trypanosomatid parasites by a modified bovine host defense peptide, BMAP-18. PLoS Negl. Trop. Dis. 2009, 3, e373.

158. WHO. Leishmaniasis Fact Sheet No. 375. February 2015. Avaliable online: http://www. who.int/mediacentre/factsheets/fs375/en/ (accessed on 18 August 2015).

159. De Menezes, J.P.; Guedes, C.E.; Petersen, A.L.; Fraga, D.B.; Veras, P.S. Advances in Development of New Treatment for Leishmaniasis. Biomed. Res. Int. 2015, 2015, doi:10.1155/2015/815023.

160. Mangoni, M.L.; Saugar, J.M.; Dellisanti, M.; Barra, D.; Simmaco, M.; Rivas, L. Temporins, small antimicrobial peptides with leishmanicidal activity. J. Biol. Chem. 2005, 280, 984-990. 
161. Chadbourne, F.L.; Raleigh, C.; Ali, H.Z.; Denny, P.W.; Cobb, S.L. Studies on the antileishmanial properties of the antimicrobial peptides temporin A, B and 1Sa. J. Pept. Sci. An Off. Publ. Eur. Pept. Soc. 2011, 17, 751-755.

162. Abbassi, F.; Oury, B.; Blasco, T.; Sereno, D.; Bolbach, G.; Nicolas, P.; Hani, K.; Amiche, M.; Ladram, A. Isolation, characterization and molecular cloning of new temporins from the skin of the North African ranid Pelophylax saharica. Peptides 2008, 29, 1526-1533.

163. Eggimann, G.A.; Sweeney, K.; Bolt, H.L.; Rozatian, N.; Cobb, S.L.; Denny, P.W. The role of phosphoglycans in the susceptibility of Leishmania mexicana to the temporin family of anti-microbial peptides. Molecules 2015, 20, 2775-2785.

164. Eaton, P.; Bittencourt, C.R.; Costa Silva, V.; Veras, L.M.; Costa, C.H.; Feio, M.J.; Leite, J.R. Anti-leishmanial activity of the antimicrobial peptide DRS 01 observed in Leishmania infantum (syn. Leishmania chagasi) cells. Nanomedicine 2014, 10, 483-490.

165. Brand, G.D.; Leite, J.R.; de Sa Mandel, S.M.; Mesquita, D.A.; Silva, L.P.; Prates, M.V.; Barbosa, E.A.; Vinecky, F.; Martins, G.R.; Galasso, J.H.; et al. Novel dermaseptins from Phyllomedusa hypochondrialis (Amphibia). Biochem. Biophys. Res. Commun. 2006, 347, 739-746.

166. Silva, P.I., Jr.; Daffre, S.; Bulet, P. Isolation and characterization of gomesin, an 18-residue cysteine-rich defense peptide from the spider Acanthoscurria gomesiana hemocytes with sequence similarities to horseshoe crab antimicrobial peptides of the tachyplesin family. J. Biol. Chem. 2000, 275, 33464-33470.

167. Bera, A.; Singh, S.; Nagaraj, R.; Vaidya, T. Induction of autophagic cell death in Leishmania donovani by antimicrobial peptides. Mol. Biochem. Parasitol. 2003, 127, 23-35.

168. Berrocal-Lobo, M.; Molina, A.; Rodriguez-Palenzuela, P.; Garcia-Olmedo, F.; Rivas, L. Leishmania donovani: Thionins, plant antimicrobial peptides with leishmanicidal activity. Exp. Parasitol. 2009, 122, 247-249.

169. Perez-Cordero, J.J.; Lozano, J.M.; Cortes, J.; Delgado, G. Leishmanicidal activity of synthetic antimicrobial peptides in an infection model with human dendritic cells. Peptides 2011, 32, 683-690.

170. Kulkarni, M.M.; McMaster, W.R.; Kamysz, E.; Kamysz, W.; Engman, D.M.; McGwire, B.S. The major surface-metalloprotease of the parasitic protozoan, Leishmania, protects against antimicrobial peptide-induced apoptotic killing. Mol. Microbiol. 2006, 62, 1484-1497.

171. Kulkarni, M.M.; McMaster, W.R.; Kamysz, W.; McGwire, B.S. Antimicrobial peptide-induced apoptotic death of leishmania results from calcium-dependent, caspase-independent mitochondrial toxicity. J. Biol. Chem. 2009, 284, 15496-15504.

172. Kulkarni, M.M.; Karafova, A.; Kamysz, W.; McGwire, B.S. Design of protease-resistant pexiganan enhances antileishmanial activity. Parasitol. Res. 2014, 113, 1971-1976.

173. WHO. Malaria. Fact Sheet No. 94 April 2015. Avaliable online: http://www.who.int/mediacentre/ factsheets/fs094/en/ (accessed on 18 August 2015).

174. WHO. Guidelines for the Treatment of Malaria. Avaliable online: http://apps.who.int/iris/ bitstream/10665/162441/1/9789241549127_eng.pdf (accessed on 18 August 2015).

175. Du Plessis, L.H.; van Niekerk, A.C.; Maritz, M.M.; Kotze, A.F. In vitro activity of Pheroid vesicles containing antibiotics against Plasmodium falciparum. J. Antibiot. 2012, 65, 609-614. 
176. Krugliak, M.; Feder, R.; Zolotarev, V.Y.; Gaidukov, L.; Dagan, A.; Ginsburg, H.; Mor, A. Antimalarial activities of dermaseptin S4 derivatives. Antimicrob. Agents Chemother. 2000, 44, 2442-2451.

177. Carter, V.; Underhill, A.; Baber, I.; Sylla, L.; Baby, M.; Larget-Thiery, I.; Zettor, A.; Bourgouin, C.; Langel, U.; Faye, I.; et al. Killer bee molecules: Antimicrobial peptides as effector molecules to target sporogonic stages of Plasmodium. PLoS Pathog. 2013, 9, e1003790.

178. Moreira, C.K.; Rodrigues, F.G.; Ghosh, A.; Varotti Fde, P.; Miranda, A.; Daffre, S.; Jacobs-Lorena, M.; Moreira, L.A. Effect of the antimicrobial peptide gomesin against different life stages of Plasmodium spp. Exp. Parasitol. 2007, 116, 346-353.

179. Parker, G.A.; Ball, M.A.; Chubb, J.C. Why do larval helminths avoid the gut of intermediate hosts? J. Theor. Biol. 2009, 260, 460-473.

180. Halton, D.W. Microscopy and the helminth parasite. Micron 2004, 35, 361-390.

181. Hotez, P.J.; Brindley, P.J.; Bethony, J.M.; King, C.H.; Pearce, E.J.; Jacobson, J. Helminth infections: The great Neglected tropical diseases J. Clin. Investig. 2008, 118, 1311-1321.

182. Awasthi, S.; Bundy, D.A.; Savioli, L. Helminthic infections. Br. Med. J. 2003, 327, 431-433.

183. Crompton, D.W.T. How Much Human Helminthiasis Is There in the World? J. Parasitol. 1999, 85, 397-403.

184. Stephenson, L.S.; Latham, M.C.; Ottesen, E.A. Malnutrition and parasitic helminth infections. Parasitology 2000, 121, S23-S38.

185. WHO. World Heatlh Report 1999; World Health Organization: Geneva, Switzerland, 1999.

186. Anthony, R.M.; Rutitzky, L.I.; Urban, J.F., Jr.; Stadecker, M.J.; Gause, W.C. Protective immune mechanisms in helminth infection. Nat. Rev. Immunol. 2007, 7, 975-987.

187. Li, T.; Ito, A.; Chen, X.; Long, C.; Okamoto, M.; Raoul, F.; Giraudoux, P.; Yanagida, T.; Nakao, M.; Sako, Y.; et al. Usefulness of pumpkin seeds combined with areca nut extract in community-based treatment of human taeniasis in northwest Sichuan Province, China. Acta Trop. 2012, 124, 152-157.

188. Flisser, A.; Avila, G.; Maravilla, P.; Mendlovic, F.; Leon-Cabrera, S.; Cruz-Rivera, M.; Garza, A.; Gomez, B.; Aguilar, L.; Teran, N.; et al. Taenia solium: Current understanding of laboratory animal models of taeniosis. Parasitology 2010, 137, 347-357.

189. Bustos, J.A.; Rodriguez, S.; Jimenez, J.A.; Moyano, L.M.; Castillo, Y.; Ayvar, V.; Allan, J.C.; Craig, P.S.; Gonzalez, A.E.; Gilman, R.H.; et al. Detection of Taenia solium Taeniasis Coproantigen Is an Early Indicator of Treatment Failure for Taeniasis. Clin. Vaccine Immunol. 2012, 19, 570-573.

190. WHO Taeniasis/ cysticercosis: Fact Sheet $\mathrm{N}^{\circ}$ 376. Available online: http://www.who.int/ mediacentre/factsheets/fs376/en/\#(accessed on 23 June 2015).

191. García, H.H.; Gonzalez, A.E.; Evans, C.A.W.; Gilman, R.H.; for the Cysticercosis Working Group in Peru. Taenia solium cysticercosis. Lancet 2003, 362, 547-556.

192. Kościuczuk, E.M.; Lisowski, P.; Jarczak, J.; Strzałkowska, N.; Jóźwik, A.; Horbańczuk, J.; Krzyżewski, J.; Zwierzchowski, L.; Bagnicka, E. Cathelicidins: Family of antimicrobial peptides. A review. Mol. Biol. Rep. 2012, 39, 10957-10970.

193. Landa, A.; Jiménez, L.; Willms, K.; Jiménez-García, L.F.; Lara-Martínez, R.; Robert, L.; Cirioni, O.; Barańska-Rybak, W.; Kamysz, W. Antimicrobial peptides (Temporin A and Iseganan IB-367): Effect on the cysticerci of Taenia crassiceps. Mol. Biochem. Parasitol. 2009, 164, 126-130. 
194. WHO Onchocerciasis: Fact Sheet $\mathrm{N}^{\circ}$ 374. Available online: http://www.who.int/mediacentre /factsheets/fs374/en/\#(accessed on 23 June 2015).

195. CDC Parasites - Onchocerciasis (also known as River Blindness). Available online: http://www. cdc.gov/parasites/onchocerciasis/ (accessed on 23 June 2015).

196. Noma, M.; Nwoke, B.E.; Nutall, I.; Tambala, P.A.; Enyong, P.; Namsenmo, A.; Remme, J.; Amazigo, U.V.; Kale, O.O.; Seketeli, A. Rapid epidemiological mapping of onchocerciasis (REMO): Its application by the African Programme for Onchocerciasis Control (APOC). Ann. Trop. Med. Parasitol. 2002, 96, S29-S39.

197. Tekle, A.H.; Elhassan, E.; Isiyaku, S.; Amazigo, U.V.; Bush, S.; Noma, M.; Cousens, S.; Abiose, A.; Remme, J. H. Impact of long-term treatment of onchocerciasis with ivermectin in Kaduna State, Nigeria: First evidence of the potential for elimination in the operational area of the African Programme for Onchocerciasis Control. Parasites Vectors 2012, 5, doi:10.1186/1756-3305-5-28.

198. Marti, T.; Erttmann, K.D.; Gallin, M.Y. Host-Parasite Interaction in Human Onchocerciasis: Identification and Sequence Analysis of a Novel Human Calgranulin. Biochem. Biophys. Res. Commun. 1996, 221, 454-458.

199. Ganz, T.; Selsted, M.E.; Szklarek, D.; Harwig, S.S.; Daher, K.; Bainton, D.F.; Lehrer, R.I. Defensins. Natural peptide antibiotics of human neutrophils. J. Clin. Investig. 1985, 76, 1427-1435.

200. Soehnlein, O.; Kai-Larsen, Y.; Frithiof, R.; Sorensen, O.E.; Kenne, E.; Scharffetter-Kochanek, K.; Eriksson, E.E.; Herwald, H.; Agerberth, B.; Lindbom, L. Neutrophil primary granule proteins HBP and HNP1-3 boost bacterial phagocytosis by human and murine macrophages. J. Clin. Investig. 2008, 118, 3491-3502.

201. Mookherjee, N.; Hancock, R.E. Cationic host defence peptides: Innate immune regulatory peptides as a novel approach for treating infections. Cell. Mol. Life Sci. 2007, 64, 922-933.

202. Gwyer Findlay, E.; Currie, S.M.; Davidson, D.J. Cationic host defence peptides: Potential as antiviral therapeutics. BioDrugs 2013, 27, 479-493.

203. De Clercq, E. Antiviral drugs: Current state of the art. J. Clin. Virol. 2001, 22, 73-89.

204. Albiol Matanic, V.C.; Castilla, V. Antiviral activity of antimicrobial cationic peptides against Junin virus and herpes simplex virus. Int. J. Antimicrob. Agents 2004, 23, 382-389.

205. Orsi, N. The antimicrobial activity of lactoferrin: Current status and perspectives. Biometals 2004, 17, 189-196.

206. Sun, L.; Finnegan, C.M.; Kish-Catalone, T.; Blumenthal, R.; Garzino-Demo, P.; la Terra Maggiore, G.M.; Berrone, S.; Kleinman, C.; Wu, Z.; Abdelwahab, S.; et al. Human beta-defensins suppress human immunodeficiency virus infection: Potential role in mucosal protection. J. Virol. 2005, 79, 14318-14329.

207. van der Strate, B.W.; Beljaars, L.; Molema, G.; Harmsen, M.C.; Meijer, D.K. Antiviral activities of lactoferrin. Antivir. Res. 2001, 52, 225-239.

208. Yasin, B.; Pang, M.; Turner, J.S.; Cho, Y.; Dinh, N.N.; Waring, A.J.; Lehrer, R.I.; Wagar, E.A. Evaluation of the inactivation of infectious Herpes simplex virus by host-defense peptides. Eur. J. Clin. Microbiol. Infect. Dis. 2000, 19, 187-194.

209. Daher, K.A.; Selsted, M.E.; Lehrer, R.I. Direct inactivation of viruses by human granulocyte defensins. J. Virol. 1986, 60, 1068-1074. 
210. Duits, L.A.; Nibbering, P.H.; van Strijen, E.; Vos, J.B.; Mannesse-Lazeroms, S.P.; van Sterkenburg, M.A.; Hiemstra, P.S. Rhinovirus increases human beta-defensin-2 and -3 mRNA expression in cultured bronchial epithelial cells. FEMS Immunol. Med. Microbiol. 2003, 38, 59-64.

211. Buck, C.B.; Day, P.M.; Thompson, C.D.; Lubkowski, J.; Lu, W.; Lowy, D.R.; Schiller, J.T. Human alpha-defensins block papillomavirus infection. Proc. Natl. Acad. Sci. USA 2006, 103, 1516-1521.

212. Carriel-Gomes, M.C.; Kratz, J.M.; Barracco, M.A.; Bachere, E.; Barardi, C.R.; Simoes, C.M. In vitro antiviral activity of antimicrobial peptides against herpes simplex virus 1, adenovirus, and rotavirus. Mem. Inst. Oswaldo Cruz 2007, 102, 469-472.

213. Edinger, A.L.; Thompson, C.B. Death by design: Apoptosis, necrosis and autophagy. Curr. Opin. Cell Biol. 2004, 16, 663-669.

214. Levy, D.E.; Marie, I.J.; Durbin, J.E. Induction and function of type I and III interferon in response to viral infection. Curr. Opin. Cell Biol. 2011, 1, 476-486.

215. Stetson, D.B.; Medzhitov, R. Type I interferons in host defense. Immunity 2006, 25, 373-381.

216. Randall, R.E.; Goodbourn, S. Interferons and viruses: An interplay between induction, signalling, antiviral responses and virus countermeasures. J. Gen. Virol. 2008, 89, doi:10.1099/vir.0.83391-0.

217. Takeuchi, O.; Akira, S. Innate immunity to virus infection. Immunol. Rev. 2009, 227, 75-86.

218. Salvatore, M.; Garcia-Sastre, A.; Ruchala, P.; Lehrer, R.I.; Chang, T.; Klotman, M.E. Alpha-Defensin inhibits influenza virus replication by cell-mediated mechanism(s). J. Infect. Dis. 2007, 196, 835-843.

219. Koczulla, A.R.; Bals, R. Antimicrobial peptides: Current status and therapeutic potential. Drugs 2003, 63, 389-406.

220. Beatty, M.E.; Stone, A.; Fitzsimons, D.W.; Hanna, J.N.; Lam, S.K.; Vong, S.; Guzman, M.G.; Mendez-Galvan, J.F.; Halstead, S.B.; Letson, G.W.; et al. Americas Dengue Prevention Boards Surveillance Working, G., Best practices in dengue surveillance: A report from the Asia-Pacific and Americas Dengue Prevention Boards. PLoS Negl.Trop. Dis. 2010, 4, e890.

221. Halstead, S.B. Dengue virus-mosquito interactions. Ann. Rev. Entomol. 2008, 53, 273-291.

222. Halstead, S.B. Pathogenesis of dengue: Challenges to molecular biology. Science 1988, 239, 476-481.

223. Normile, D. Tropical medicine. Surprising new dengue virus throws a spanner in disease control efforts. Science 2013, 342, doi:10.1126/science.342.6157.415.

224. Vasilakis, N.; Holmes, E.C.; Fokam, E.B.; Faye, O.; Diallo, M.; Sall, A.A.; Weaver, S.C. Evolutionary processes among sylvatic dengue type 2 viruses. J. Virol. 2007, 81, 9591-9595.

225. Rodenhuis-Zybert, I.A.; Wilschut, J.; Smit, J.M. Dengue virus life cycle: Viral and host factors modulating infectivity. Cell. Mol. Life Sci. 2010, 67, 2773-2786.

226. Steinhauer, D.A.; Domingo, E.; Holland, J.J. Lack of evidence for proofreading mechanisms associated with an RNA virus polymerase. Gene 1992, 122, 281-288.

227. Wittke, V.; Robb, T.E.; Thu, H.M.; Nisalak, A.; Nimmannitya, S.; Kalayanrooj, S.; Vaughn, D.W.; Endy, T.P.; Holmes, E.C.; Aaskov, J.G. Extinction and rapid emergence of strains of dengue 3 virus during an interepidemic period. Virology 2002, 301, 148-156. 
228. CDC. Dengue and the Aedes aegypti Mosquito. Avaliable online: http://www.cdc.gov/dengue/ resources/30Jan2012/aegyptifactsheet.pdf (accessed on 21 August 2015).

229. Bhatt, S.; Gething, P.W.; Brady, O.J.; Messina, J.P.; Farlow, A.W.; Moyes, C.L.; Drake, J.M.; Brownstein, J.S.; Hoen, A.G.; Sankoh, O.; et al. The global distribution and burden of dengue. Nature 2013, 496, 504-507.

230. Shepard, D.S.; Undurraga, E.A.; Halasa, Y.A. Economic and disease burden of dengue in Southeast Asia. PLoS Negl.Trop. Dis. 2013, 7, e2055.

231. Rothman, A.L. Immunity to dengue virus: A tale of original antigenic sin and tropical cytokine storms. Nat. Rev. Immunol. 2011, 11, 532-543.

232. Kozlov, S.A.; Vassilevski, A.A.; Feofanov, A.V.; Surovoy, A.Y.; Karpunin, D.V.; Grishin, E.V. Latarcins, antimicrobial and cytolytic peptides from the venom of the spider Lachesana tarabaevi (Zodariidae) that exemplify biomolecular diversity. J. Biol. Chem. 2006, 281, 20983-20992.

233. Rothan, H.A.; Bahrani, H.; Rahman, N.A.; Yusof, R. Identification of natural antimicrobial agents to treat dengue infection: In vitro analysis of latarcin peptide activity against dengue virus. BMC Microbiol. 2014, 14, doi:10.1186/1471-2180-14-140.

234. Lindenbach, B.D.; Rice, C.M. Molecular biology of flaviviruses. Adv. Virus Res. 2003, 59, 23-61.

235. Perera, R.; Kuhn, R.J. Structural proteomics of dengue virus. Curr. Opin. Microbiol. 2008, 11, 369-377.

236. Noble, C.G.; Seh, C.C.; Chao, A.T.; Shi, P.Y. Ligand-bound structures of the dengue virus protease reveal the active conformation. J. Virol. 2012, 86, 438-446.

237. Alhoot, M.A.; Rathinam, A.K.; Wang, S.M.; Manikam, R.; Sekaran, S.D. Inhibition of dengue virus entry into target cells using synthetic antiviral peptides. Int. J. Med. Sci. 2013, 10, 719-729.

238. Chen, Y.; Maguire, T.; Marks, R.M. Demonstration of binding of dengue virus envelope protein to target cells. J. Virol. 1996, 70, 8765-8772.

239. Modis, Y.; Ogata, S.; Clements, D.; Harrison, S.C. Structure of the dengue virus envelope protein after membrane fusion. Nature 2004, 427, 313-319.

240. Wallace, R.M.; Gilbert, A.; Slate, D.; Chipman, R.; Singh, A.; Cassie, W.; Blanton, J.D. Right place, wrong species: A 20-year review of rabies virus cross species transmission among terrestrial mammals in the United States. PLoS ONE 2014, 9, e107539.

241. Cleaveland, S.; Fevre, E.M.; Kaare, M.; Coleman, P.G. Estimating human rabies mortality in the United Republic of Tanzania from dog bite injuries. Bull. World Health Organ. 2002, 80, 304-310.

242. Schnell, M.J.; McGettigan, J.P.; Wirblich, C.; Papaneri, A. The cell biology of rabies virus: Using stealth to reach the brain. Nat. Rev. Microbiol. 2010, 8, 51-61.

243. WHO. Rabies Fact Sheet $N^{\circ}$ 99. Available online: http://www.who.int/mediacentre/factsheets/ fs099/en/(accessed on 18 August 2015).

244. Lyles, D.S.; Rupprecht, C.E. Rhabdoviridae. Fields'Virology; Fields, B.N., Knipe, D.M., Howley, P.M., Griffin, D.E., Lamb, R.A., Martin, M.A., Roizman, B., Straus, S.E., Eds.; Williams and Wilkins: Philadelphia, PA, USA, 2007; Volume 4, pp. 1364-1408.

245. Brzozka, K.; Finke, S.; Conzelmann, K.K. Identification of the rabies virus alpha/beta interferon antagonist: Phosphoprotein $\mathrm{P}$ interferes with phosphorylation of interferon regulatory factor 3. J. Virol. 2005, 79, 7673-7681. 
246. Kelly, R.M.; Strick, P.L. Rabies as a transneuronal tracer of circuits in the central nervous system. J. Neurosci. Methods 2000, 103, 63-71.

247. Warrell, D.A. The clinical picture of rabies in man. Trans. R. Soc. Trop. Med. Hyg. 1976, 70, $188-195$.

248. Manning, S.E.; Rupprecht, C.E.; Fishbein, D.; Hanlon, C.A.; Lumlertdacha, B.; Guerra, M.; Meltzer, M.I.; Dhankhar, P.; Vaidya, S.A.; Jenkins, S.R.; et al. Advisory Committee on Immunization Practices Centers for Disease, C.; Prevention, Human rabies prevention-United States, 2008: Recommendations of the Advisory Committee on Immunization Practices. MMWR Recomm. Rep. 2008, 57, 1-28.

249. Cenna, J.; Tan, G.S.; Papaneri, A.B.; Dietzschold, B.; Schnell, M.J.; McGettigan, J.P. Immune modulating effect by a phosphoprotein-deleted rabies virus vaccine vector expressing two copies of the rabies virus glycoprotein gene. Vaccine 2008, 26, 6405-6414.

250. Lodmell, D.L.; Parnell, M.J.; Bailey, J.R.; Ewalt, L.C.; Hanlon, C.A. Rabies DNA vaccination of non-human primates: Post-exposure studies using gene gun methodology that accelerates induction of neutralizing antibody and enhances neutralizing antibody titers. Vaccine 2002, 20, 2221-2228.

251. Dodet, B.; Africa Rabies Expert, B.; Adjogoua, E.V.; Aguemon, A.R.; Amadou, O.H.; Atipo, A.L.; Baba, B.A.; Ada, S.B.; Boumandouki, P.; Bourhy, H.; et al. Fighting rabies in Africa: The Africa Rabies Expert Bureau (AfroREB). Vaccine 2008, 26, 6295-6298.

252. Real, E.; Rain, J.C.; Battaglia, V.; Jallet, C.; Perrin, P.; Tordo, N.; Chrisment, P.; D’Alayer, J.; Legrain, P.; Jacob, Y. Antiviral drug discovery strategy using combinatorial libraries of structurally constrained peptides. J. Virol. 2004, 78, 7410-7417.

253. A Database of Antiviral Peptides: Available online: http://crdd.osdd.net/servers/avpdb/ browse.php?by=Rabies\%20virus\&TYPE=Virus (accessed on 21 August 2015).

254. Jacob, Y.; Real, E.; Tordo, N. Functional interaction map of lyssavirus phosphoprotein: Identification of the minimal transcription domains. J. Virol. 2001, 75, 9613-9622.

255. Wojczyk, B.S.; Stwora-Wojczyk, M.; Shakin-Eshleman, S.; Wunner, W.H.; Spitalnik, S.L. The role of site-specific $\mathrm{N}$-glycosylation in secretion of soluble forms of rabies virus glycoprotein. Glycobiology 1998, 8, 121-130.

256. Rodriguez Saint-Jean, S.; De las Heras, A.; Carrillo, W.; Recio, I.; Ortiz-Delgado, J.B.; Ramos, M.; Gomez-Ruiz, J.A.; Sarasquete, C.; Perez-Prieto, S.I., Antiviral activity of casein and alphas 2 casein hydrolysates against the infectious haematopoietic necrosis virus, a rhabdovirus from salmonid fish. J. Fish Dis. 2013, 36, 467-481.

257. Falco, A.; Mas, V.; Tafalla, C.; Perez, L.; Coll, J.M.; Estepa, A. Dual antiviral activity of human alpha-defensin-1 against viral haemorrhagic septicaemia rhabdovirus (VHSV): Inactivation of virus particles and induction of a type I interferon-related response. Antivir. Res. 2007, 76, 111-123.

258. Ali, M.P.; Yoshimatsu, K.; Suzuki, T.; Kato, T.; Park, E.Y. Expression and purification of cyto-insectotoxin (Cit1a) using silkworm larvae targeting for an antimicrobial therapeutic agent. Appl. Microbiol. Biotechnol. 2014, 98, 6973-6982.

259. Bommarius, B.; Jenssen, H.; Elliott, M.; Kindrachuk, J.; Pasupuleti, M.; Gieren, H.; Jaeger, K.E.; Hancock, R.E.; Kalman, D. Cost-effective expression and purification of antimicrobial and host defense peptides in Escherichia coli. Peptides 2010, 31, 1957-1965. 
260. Li, Y. Recombinant production of antimicrobial peptides in Escherichia coli: A review. Protein Expr. Purif. 2011, 80, 260-267.

(C) 2015 by the authors; licensee MDPI, Basel, Switzerland. This article is an open access article distributed under the terms and conditions of the Creative Commons Attribusstion license (http://creativecommons.org/licenses/by/4.0/). 